\title{
Evaluating the impact of new observational constraints on P-S/IVOC emissions, multi-generation oxidation, and chamber wall losses on SOA modeling for Los Angeles, CA
}

\author{
Prettiny K. Ma ${ }^{1}$, Yunliang Zhao ${ }^{2}$, Allen L. Robinson ${ }^{2}$, David R. Worton ${ }^{3, a}$, Allen H. Goldstein ${ }^{3,4}$, Amber M. Ortega ${ }^{5, b}$ \\ Jose L. Jimenez ${ }^{5}$, Peter Zotter ${ }^{6, c}$, André S. H. Prévôt ${ }^{6}$, Sönke Szidat ${ }^{7}$, and Patrick L. Hayes ${ }^{1}$ \\ ${ }^{1}$ Department of Chemistry, Université de Montréal, Montréal, QC, Canada \\ ${ }^{2}$ Center for Atmospheric Particle Studies, Carnegie Mellon University, Pittsburgh, PA, USA \\ ${ }^{3}$ Department of Environmental Science, Policy and Management, University of California, Berkeley, CA, USA \\ ${ }^{4}$ Department of Civil and Environmental Engineering, University of California, Berkeley, CA, USA \\ ${ }^{5}$ Cooperative Institute for Research in the Environmental Sciences and Dept. of Chemistry and Biochemistry, \\ University of Colorado, Boulder, CO, USA \\ ${ }^{6}$ Laboratory of Atmospheric Chemistry, Paul Scherrer Institute, Villigen, Switzerland \\ ${ }^{7}$ Department of Chemistry and Biochemistry \& Oeschger Centre for Climate Change, University of Bern, Bern, Switzerland \\ anow at: National Physical Laboratory, Hampton Rd, Teddington, Middlesex, UK \\ ${ }^{b}$ now at: Air Pollution Control Division, Colorado Department of Public Health and Environment, Denver, CO, USA \\ ${ }^{c}$ now at: Lucerne University of Applied Sciences and Arts, School of Engineering and Architecture, Bioenergy Research, \\ Technikumstrasse 21, 6048 Horw, Switzerland
}

Correspondence to: Patrick L. Hayes (patrick.hayes@umontreal.ca)

Received: 26 October 2016 - Discussion started: 11 November 2016

Revised: 23 May 2017 - Accepted: 7 June 2017 - Published: 1 August 2017

\begin{abstract}
Secondary organic aerosol (SOA) is an important contributor to fine particulate matter (PM) mass in polluted regions, and its modeling remains poorly constrained. A box model is developed that uses recently published literature parameterizations and data sets to better constrain and evaluate the formation pathways and precursors of urban SOA during the CalNex 2010 campaign in Los Angeles. When using the measurements of intermediate-volatility organic compounds (IVOCs) reported in Zhao et al. (2014) and of semivolatile organic compounds (SVOCs) reported in Worton et al. (2014) the model is biased high at longer photochemical ages, whereas at shorter photochemical ages it is biased low, if the yields for VOC oxidation are not updated. The parameterizations using an updated version of the yields, which takes into account the effect of gas-phase wall losses in environmental chambers, show model-measurement agreement at longer photochemical ages, even though some low bias at short photochemical ages still remains. Furthermore, the fossil and non-fossil carbon split of urban SOA simulated by
\end{abstract}

the model is consistent with measurements at the Pasadena ground site.

Multi-generation oxidation mechanisms are often employed in SOA models to increase the SOA yields derived from environmental chamber experiments in order to obtain better model-measurement agreement. However, there are many uncertainties associated with these aging mechanisms. Thus, SOA formation in the model is compared to data from an oxidation flow reactor (OFR) in order to constrain SOA formation at longer photochemical ages than observed in urban air. The model predicts similar SOA mass at short to moderate photochemical ages when the aging mechanisms or the updated version of the yields for VOC oxidation are implemented. The latter case has SOA formation rates that are more consistent with observations from the OFR though. Aging mechanisms may still play an important role in SOA chemistry, but the additional mass formed by functionalization reactions during aging would need to be offset by gasphase fragmentation of SVOCs. 
All the model cases evaluated in this work show a large majority of the urban SOA (70-83\%) at Pasadena coming from the oxidation of primary SVOCs (P-SVOCs) and primary IVOCs (P-IVOCs). The importance of these two types of precursors is further supported by analyzing the percentage of SOA formed at long photochemical ages (1.5 days) as a function of the precursor rate constant. The P-SVOCs and $\mathrm{P}-\mathrm{IVOCs}$ have rate constants that are similar to highly reactive VOCs that have been previously found to strongly correlate with SOA formation potential measured by the OFR.

Finally, the volatility distribution of the total organic mass (gas and particle phase) in the model is compared against measurements. The total SVOC mass simulated is similar to the measurements, but there are important differences in the measured and modeled volatility distributions. A likely reason for the difference is the lack of particle-phase reactions in the model that can oligomerize and/or continue to oxidize organic compounds even after they partition to the particle phase.

\section{Introduction}

Atmospheric aerosols are important climate forcing agents (Christensen et al., 2013), negatively impact human health (Dockery and Pope, 1994), and reduce visibility by scattering and absorbing light (Watson, 2002). However, quantitatively predicting the composition and concentrations of aerosols is challenging, in part because of their complex composition and the variety of emission sources and chemical pathways that contribute to aerosol loadings in the atmosphere (Heald et al., 2011; Spracklen et al., 2011). Atmospheric aerosols are composed of black carbon and inorganic and organic matter, and the latter is a mixture of hundreds to thousands of compounds (Gentner et al., 2012).

Due to this complexity, organic aerosol is often categorized into two groups. Primary organic aerosol (POA) is directly emitted into the atmosphere from sources such as motor vehicles, food cooking, and biomass burning (Hallquist et al., 2009). Conversely, secondary organic aerosol (SOA) is the product of diverse chemical reactions occurring in the atmosphere that transform more-volatile precursors such as volatile organic compounds (VOCs) into lower-volatility products that are either incorporated into existing particles or form new particles. Many previous studies have shown that SOA is an important fraction of OA, often representing more than half the total OA concentration (Zhang et al., 2007; Jimenez et al., 2009).

In SOA parameterizations for use in regional and global models, a semiempirical approach is used in which VOCs, often the only SOA precursors considered, react with $\mathrm{OH}$ radicals and other oxidants to form secondary products with lower volatility at a given mass yield. These secondary semivolatile organic compounds (SVOCs) can partition to the par- ticle phase to form SOA (Pankow, 1994; Odum et al., 1996; Donahue et al., 2006). The parameters used in the models for the VOCs, such as the yields and product volatilities, are often determined from published chamber studies (e.g., Kroll et al., 2006; Chan et al., 2009; Hallquist et al., 2009; Presto et al., 2010). Over the past decade a number of studies have shown that traditional models that consider only the oxidation of VOCs alone predict SOA concentrations much lower than those observed in polluted urban regions (Volkamer et al., 2006; Dzepina et al., 2009; Hodzic and Jimenez, 2011; Hayes et al., 2015). As a result, several updates have been proposed in the literature to improve SOA models, including new pathways for SOA formation, new SOA precursors, and increased yields for known precursors (e.g., $\mathrm{Ng}$ et al., 2007; Robinson et al., 2007; Ervens and Volkamer, 2010).

The volatility basis set (VBS) approach (Donahue et al., 2006) has been used in most recent parameterizations of SOA yields. In this approach, the organic mass is distributed in logarithmically spaced volatility bins, and the SOA-forming reactions then redistribute the mass from precursors such as anthropogenic and biogenic VOCs into bins with generally lower volatility (except for fragmentation reactions), leading to increased OA concentrations (Robinson et al., 2007; Tsimpidi et al., 2010). While the VBS provides a valuable conceptual framework for SOA modeling, substantial uncertainties remain in the correct parameters for different precursors and conditions.

In this paper we focus on investigating three interrelated questions that are responsible for important uncertainties in urban SOA modeling. The first is how to best incorporate SOA from primary semi-volatile and intermediate-volatility compounds (P-S/IVOCs), two recently proposed types of SOA precursors. While there is now ample evidence that $\mathrm{P}$ S/IVOCs are important contributors to SOA (Robinson et al., 2007; Zhao et al., 2014; Dunmore et al., 2015; Ots et al., 2016), the emissions of these precursors as well as the parameters that govern their oxidation and SOA formation are not well constrained. Also, it is well known that models of SOA that incorporate P-S/IVOCs often do not agree with measurements across a range of photochemical ages, although the modeled SOA mass varies substantially with the parameterization used (Dzepina et al., 2009; Hayes et al., 2015; Fountoukis et al., 2016; Woody et al., 2016). The second question is whether losses of semi-volatile gases to the walls of environmental chambers (Matsunaga and Ziemann, 2010; Krechmer et al., 2016) have resulted in low biases for the yields of some or all precursors, especially VOCs, as has been recently reported (Zhang et al., 2014). The third question is the appropriateness of including aging mechanisms in the VBS parameterization of SOA from VOCs, in which the initial oxidation reaction is followed by subsequent oxidation reactions of the first- and later-generation products, with each reaction resulting in a reduction of the organic volatility by, for example, an order of magnitude. These aging mechanisms increase VOC 
yields to levels much higher than those observed in chamber studies since it was perceived that the yields may be too low in chambers compared to the real atmosphere. The aging mechanisms were added to chamber yields that were obtained without using aging as part of the fits of the chamber data. In some model applications they improve model agreement with field measurements (Ahmadov et al., 2012), while at long photochemical ages they lead to model SOA formation that is substantially larger than observed (e.g., Dzepina et al., 2011; Hayes et al., 2015). While the inclusion of some of these new SOA precursors, updated yields, and aging can provide better agreement with measurements in some cases, the relative amount of SOA formed from VOCs (V-SOA), P-IVOCs (I-SOA), and P-SVOCs (S-SOA) is highly uncertain and changes strongly depending on which of the updates above is implemented in a specific model. In addition, the fact that different subsets and variants of these updates can allow specific models to match SOA measurements raises important questions regarding whether or not the model mechanisms are representative of actual SOA-forming processes in the atmosphere.

The notation used when discussing SOA precursors in this paper is similar to Hayes et al. (2015). We differentiate VOCs, IVOCs, and SVOCs by their effective saturation concentration $\left(c^{*}\right)$. Therefore, SVOCs and IVOCs have volatilities ranging from $c^{*}=10^{-2}$ to $10^{2}$ and from $10^{3}$ to $10^{6} \mu \mathrm{g} \mathrm{m}^{-3}$ respectively, while VOCs are in the bins of $c^{*} \geq 10^{7} \mu \mathrm{g} \mathrm{m}{ }^{-3}$.

Recently, we evaluated three parameterizations for the formation of S-SOA and I-SOA using a constrained 0-D box model that represents the South Coast Air Basin during the California Research at the Nexus of Air Quality and Climate Change (CalNex) campaign (Hayes et al., 2015). Box models are often used to compare with ambient measurements and have been shown to be of similar usefulness or even superior to 3-D models if the emissions and atmospheric transport affecting a given case study are well constrained and if the use of ratios to tracers can be used to approximately account for dispersion (e.g., Volkamer et al., 2006; Dzepina et al., 2009; Hayes et al., 2015; Yuan et al., 2015). A box model allows the evaluation of multiple model parameterizations either previously proposed in the literature or developed from recent field and laboratory data sets, as well as the performance of sensitivity studies, all of which would be difficult to carry out in more computationally demanding gridded 3-D models. There are six model cases presented in this paper that are described in further detail below. Given the number of model cases (including three additional model cases from Hayes et al., 2015), it would be very computationally expensive to use a 3-D model to evaluate all the cases.

Moreover, there are important limitations to traditional comparisons of 3-D models' predicted concentrations against measurements, as for example discussed for the Pasadena ground site in Woody et al. (2016). In that study, the SOA predicted by the Community Multiscale Air Qual- ity (CMAQ) model with a VBS treatment of OA is a factor of 5.4 lower than the measurements during the midday peak in SOA concentrations. This underestimation was attributed to several different factors. First, the model photochemical age for the site was too low by a factor of 1.5 . In the box model presented in this current work, that problem is eliminated as the photochemical aging of the urban emissions in the model is instead determined from the measured ratio of 1,2,4-trimethylbenzene to benzene as described previously (Parrish et al., 2007; Hayes et al., 2013). Second, it is difficult to distinguish errors due to model dispersion from those due to emission inventories and photochemical age. Woody et al. (2016) conclude that excessive dispersion or low emissions account for an error of about a factor of 2. Those errors are also eliminated by the use of emission ratios in this work. After those errors are accounted for, by analyzing the 3-D model output using similar techniques as in our box model, the real underprediction of SOA formation efficiency by a factor of 1.8 emerged, compared to the initial value of 5.4 from the concentration comparisons. These errors (of approximately $300 \%$ ) in the interpretation of 3D model comparisons, which are ignored in most 3-D model studies, are far larger than the uncertainties due to emission ratios or dispersion in our box model (about 10-20\%), as demonstrated in Sect. 2.4.

In addition, there are uncertainties in the P-S/IVOC emissions inventories used in 3-D models and in the methods used to estimate P-S/IVOC emissions from the traditional POA inventories. In our box model, as described in further detail below, we incorporated recently published field measurements of P-S/IVOCs to better constrain the concentration of these species. Thus, while 3-D models are essential for simulating spatially and temporally complex environments under the influence of many sources, in cases where transport is relatively simple and there is a well-defined urban plume such as in Pasadena during the CalNex campaign, the box model is a valuable complementary or even superior approach that is less susceptible to the convoluted uncertainties in 3-D models discussed above. Another reason to use a box model is that it allows a direct comparison to oxidation flow reactor (OFR) measurements taken in the field (Ortega et al., 2016). The OFR provided (every $20 \mathrm{~min}$ at the Pasadena ground site) a measurement of SOA formation potential for a photochemical age of up to 2 weeks. To the best of our knowledge, 3-D models have not yet been adapted for comparison with OFR data. Finally, box models are more widely usable for experimental groups (such as ours) due to reduced complexity, while 3-D models are almost exclusively used by modelingonly groups, who tend to be more distant from the availability, use, and interpretation of experimental constraints. Thus, the use of a range of models by a range of different groups is highly beneficial to scientific progress.

The results obtained in our previous work (Hayes et al., 2015) using a box model indicated that different combinations of parameterizations could reproduce the total SOA 
equally well even though the amounts of V-SOA, I-SOA, and S-SOA were very different. In addition, the model overpredicted SOA formed at longer photochemical ages $(\approx 3$ days $)$ when compared to observations downwind of multiple urban sites. This discrepancy suggests that the ratio of P-S/IVOCs to POA may have been too high in the parameterizations evaluated. Also, as mentioned previously and discussed in Hayes et al. (2015), the implementation of aging for VOC products remains uncertain.

The goal of this study is to use several recently published results to better evaluate and constrain the box model introduced in our previous work and thus facilitate the identification of parameterizations that can eventually be incorporated into 3-D air quality models to accurately predict SOA for the right reasons. It is important to note that parameterizations used in the box model are based on several published measurements taken from laboratory experiments and field studies that provide more realistic constraints than in previous versions and that were not available to be implemented in Hayes et al. (2015). In particular, our work here improves the box model by incorporating recently published measurements of P-IVOCs and P-SVOCs that allow better estimation of the concentration, reactivity, yields, and volatility of these precursors (Worton et al., 2014; Zhao et al., 2014). In addition, given that experiments in environmental chambers may underestimate SOA yields for the VOCs due to losses of semi-volatile gases to the chamber walls (Zhang et al., 2014), the SOA yields from VOCs have been reestimated using a very recent parameterization of these wall losses (Krechmer et al., 2016). The wall-loss-corrected yields obtained are then used in the model in a sensitivity study to evaluate the corresponding change in the modeled SOA concentrations. The model is modified based on these literature constraints. No model tuning is performed with the goal of improving the agreement with the observations. The results obtained from the new box model are compared against ambient ground site and airborne measurements and also against recently published OFR measurements (Ortega et al., 2016). This combination of data sets allows the model to be evaluated for photochemical ages ranging up to 3 equivalent days (at $1.5 \times 10^{6} \mathrm{molec} \mathrm{OH} \mathrm{cm}^{-3}$ ), providing a means of evaluating the aging mechanisms of the VOCs in the VBS.

\section{Experimental section}

\subsection{Measurement and sampling site}

The box model is constructed in order to represent the South Coast Air Basin during CalNex in spring-summer 2010. The measurements of aerosols used in this study were conducted in Pasadena, California $\left(34.1406^{\circ} \mathrm{N}, 118.1224^{\circ} \mathrm{W}\right)$, located to the northeast of downtown Los Angeles (Hayes et al., 2015). An overview of CalNex has been published previously (Ryerson et al., 2013). The location and the meteorology of the ground site at Pasadena are described in further detail in Hayes et al. (2013). Pasadena is a receptor site for pollution due to winds that transport emissions from the ports of Los Angeles and Long Beach and downtown Los Angeles. Airborne measurements of aerosols were also carried out in the South Coast Air Basin as part of the CalNex project. A detailed description of the airborne measurements is given in Bahreini et al. (2012). Furthermore, measurements of POA composition and volatility taken at the Caldecott Tunnel in the San Francisco Bay area reported in previous work (Worton et al., 2014) are also used to constrain the model as described below. The tunnel air samples were collected during July 2010.

Two additional data sets are used to evaluate the model. In addition to sampling ambient air, an aerosol mass spectrometer (AMS) sampled air that had been photochemically aged using an OFR (Ortega et al., 2016). The OFR exposed ambient air to varying concentrations of $\mathrm{OH}$ radicals in order to obtain photochemical ages much higher than the ambient levels observed at the Pasadena site, and the amount of SOA produced was quantified as a function of $\mathrm{OH}$ exposure. Moreover, radiocarbon $\left({ }^{14} \mathrm{C}\right)$ analysis has been performed on filter samples and results were combined with positive matrix factorization (PMF) data to determine fossil and nonfossil fractions of the SOA components as reported in Zotter et al. (2014). The ${ }^{14} \mathrm{C}$ results are used for subsequent comparison against the box model from which fossil and non-fossil SOA mass can be estimated.

\subsection{Model setup}

The SOA model is set up to include three types of precursors: VOCs, P-IVOCs, and P-SVOCs. The parameters used in the box model to simulate the formation of SOA from these precursors are listed in Tables S1 to S3 of the Supplement. The box model dynamically calculates the evolution of organic species in an air parcel as it undergoes photochemical aging, hence producing SOA. The total SOA also includes background SOA (BG-SOA) at a constant concentration of $2.1 \mathrm{\mu g} \mathrm{m}^{-3}$, as determined in our previous work (Hayes et al., 2015). The model accounts for P-SVOC emissions from vehicular exhaust and cooking and treats POA as semi-volatile (Robinson et al., 2007). It should be noted that the model uses $\mathrm{CO}$ and $\mathrm{NO}_{x}$ as inputs to constrain the model, and the SOA yields for high- $\mathrm{NO}_{X}$ conditions are used, based on our previous work (Hayes et al., 2013, 2015). Therefore, to verify model performance, both predictions of VOC and POA concentrations have been compared against field measurements and the model performance appears to be satisfactory (Hayes et al., 2015).

A schematic of the model is shown in Fig. 1. All the model cases are listed in Table 1, and all the parameterizations are shown schematically in Fig. 2. The first model case (ROB + TSI) incorporates the Robinson et al. (2007) parameterization for SOA formation that models P-IVOCs 
Table 1. Summary of the model cases used in this paper.

\begin{tabular}{|c|c|c|}
\hline Case & Notes & References \\
\hline 1. ROB + TSI & $\begin{array}{l}\text { P-S/IVOCs: Robinson et al. parameterization, and all SOA treated } \\
\text { within VBS framework } \\
\text { VOCs: Tsimpidi et al. parameterization with aging }\end{array}$ & $\begin{array}{l}\text { Hayes et al. (2015) } \\
\text { Robinson et al. (2007) } \\
\text { Tsimpidi et al. (2010) }\end{array}$ \\
\hline 2. $\mathrm{ROB}+\mathrm{ZHAO}+\mathrm{TSI}$ & $\begin{array}{l}\text { P-SVOCs: Robinson et al. parameterization, and all SOA treated within } \\
\text { VBS framework } \\
\text { P-IVOCs: Zhao et al. parameterization with aging } \\
\text { VOCs: Tsimpidi et al. parameterization with aging }\end{array}$ & $\begin{array}{l}\text { Robinson et al. (2007) } \\
\text { Zhao et al. (2014) } \\
\text { Tsimpidi et al. (2010) }\end{array}$ \\
\hline 3. $\mathrm{WOR}+\mathrm{ZHAO}+\mathrm{TSI}$ & $\begin{array}{l}\text { P-SVOCs: Worton et al. volatility distribution for vehicular P-SVOCs, } \\
\text { Robinson et al. volatility distribution for cooking P-SVOCs } \\
\text { P-IVOCs: Zhao et al. parameterization with aging } \\
\text { VOCs: Tsimpidi et al. parameterization with aging }\end{array}$ & $\begin{array}{l}\text { Robinson et al. (2007) } \\
\text { Worton et al. (2014) } \\
\text { Zhao et al. (2014) } \\
\text { Tsimpidi et al. (2010) }\end{array}$ \\
\hline 4. $\mathrm{ROB}+\mathrm{MA}$ & $\begin{array}{l}\text { P-S/IVOCs: Robinson et al. parameterization, and all SOA treated } \\
\text { within VBS framework } \\
\text { VOCs: VOC yields corrected for wall losses, no aging of VOC oxida- } \\
\text { tion products }\end{array}$ & $\begin{array}{l}\text { Robinson et al. (2007) } \\
\text { This work }\end{array}$ \\
\hline 5. $\mathrm{ROB}+\mathrm{ZHAO}+\mathrm{MA}$ & $\begin{array}{l}\text { P-SVOCs: Robinson et al. parameterization, and all SOA treated within } \\
\text { VBS framework } \\
\text { P-IVOCs: Zhao et al. IVOC parameterization with aging } \\
\text { VOCs: VOC yields corrected for wall losses, no aging of VOC oxidation } \\
\text { products }\end{array}$ & $\begin{array}{l}\text { Robinson et al. (2007) } \\
\text { Zhao et al. (2014) } \\
\text { This work }\end{array}$ \\
\hline 6. $\mathrm{WOR}+\mathrm{ZHAO}+\mathrm{MA}$ & $\begin{array}{l}\text { P-SVOCs: Worton et al. volatility distribution for vehicular P-SVOCs, } \\
\text { Robinson et al. volatility distribution for cooking P-SVOCs } \\
\text { P-IVOCs: Zhao et al. IVOC parameterization with aging } \\
\text { VOCs: VOC yields corrected for wall losses, no aging of VOC oxidation } \\
\text { products }\end{array}$ & $\begin{array}{l}\text { Robinson et al. (2007) } \\
\text { Worton et al. (2014) } \\
\text { Zhao et al. (2014) } \\
\text { This work }\end{array}$ \\
\hline
\end{tabular}

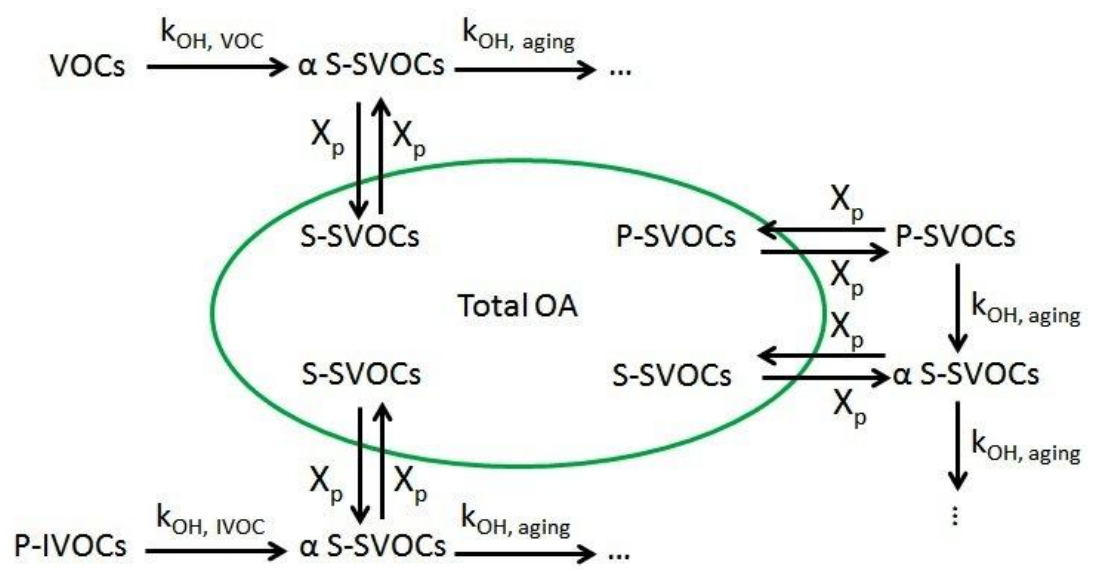

Figure 1. Schematic of the chemical pathways leading to the formation of SOA in the box model, in which $\alpha$ is the SOA yield, $k_{\mathrm{OH}, \mathrm{VOC}}$ and $k_{\mathrm{OH}, \mathrm{IVOC}}$ are the rate constants of a VOC or an IVOC species, respectively, for oxidation by $\mathrm{OH}$ radicals, and $X_{\mathrm{p}}$ is the particle-phase fraction of a species.

and P-SVOCs (i.e., P-S/IVOCs) using a single volatility distribution and oxidation rate constant. The ROB + TSI case also uses the Tsimpidi et al. (2010) parameterization for SOA formation from VOCs. A detailed description of the parameters used in ROB + TSI can be found in Hayes et al. (2015), and the ROB + TSI model case used here is identical to the case of the same name used in that paper. Briefly, as displayed in Fig. 2a, the Tsimpidi et al. (2010) parameterization proposes that the VOCs undergo an initial oxidation step that will form four lumped products with different volatilities 

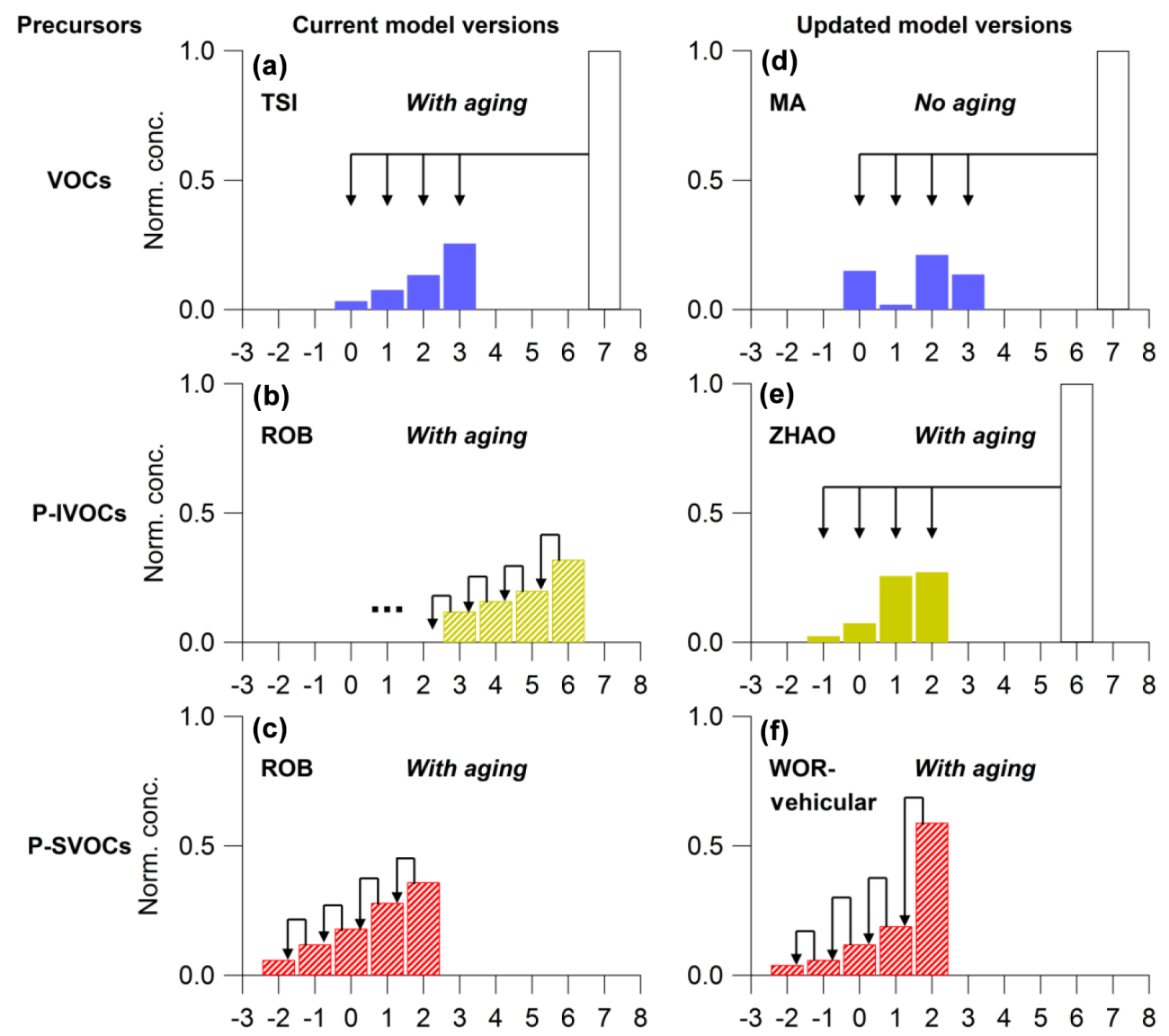

$\log c^{*}$ (saturation concentration, $\mu \mathrm{g} \mathrm{m}^{-3}$ )

Figure 2. Schematic of the SOA formation parameterizations used in the model. The products formed are shown in different colors for each precursor. Note that the striped color bars indicate that the bins contain both primary and secondary organics. In panel (a) the parameterization of Tsimpidi et al. (2010) distributes the products of VOC oxidation into four volatility bins. Panels (b, c) show the parameterization of Robinson et al. (2007) in which the volatility of the SOA precursors, specifically IVOCs and SVOCs, decreases by 1 order of magnitude per oxidation reaction. For P-IVOCs, aging continues to transfer mass to lower-volatility bins $\left(\log c^{*}<2\right)$. Panel (d) shows the updated parameterization for VOC oxidation that accounts for gas -phase wall losses, and panel (e) shows the updated parameterization for P-IVOC oxidation that uses the speciated measurements of IVOCs from Zhao et al. (2014). In panel (f), for the parameterization based on the measurements of Worton et al. (2014), the Robinson et al. (2007) volatility distribution is still used for the P-SVOCs emitted from cooking sources. Arrows representing the aging of SOA are omitted for clarity.

$\left(c^{*}=1,10^{1}, 10^{2}, 10^{3} \mu \mathrm{g} \mathrm{m}{ }^{-3}\right.$, where $c^{*}$ is the effective saturation concentration). The first-generation oxidation products can be further oxidized, decreasing their volatility by 1 order of magnitude (i.e., aging). This "bin-hopping" mechanism repeats until the lowest-volatility product is reached $\left(c^{*}=10^{-1} \mu \mathrm{g} \mathrm{m}^{-3}\right.$ in this study and $1 \mu \mathrm{g} \mathrm{m}^{-3}$ in other studies such as Tsimpidi et al. (2010) and Hayes et al. (2015). The Robinson et al. (2007) parameterization proposes that the PS/IVOCs are initially distributed in logarithmically spaced volatility bins ranging from $c^{*}=10^{-2}$ to $10^{6} \mu \mathrm{g} \mathrm{m}{ }^{-3}$. Thereafter, the oxidation of P-S/IVOCs decreases their volatility by 1 order of magnitude until the lowest-volatility product is reached $\left(c^{*}=10^{-2} \mu \mathrm{g} \mathrm{m}^{-3}\right)$. The lowest-volatility product possible is not the same for the oxidation of VOCs vs. the oxidation of the P-S/IVOCs $\left(10^{-1}\right.$ vs. $10^{-2} \mu \mathrm{g} \mathrm{m}{ }^{-3}$, respec- tively). However, whether the mass is distributed into either bin has a negligible effect on the SOA mass simulated in the box model because of the relatively high SOA concentrations during the case study.

In this work, five model parameterizations are tested that incorporate new measurements of IVOCs and P-SVOC volatility as well as updated VOC yields that account for wall losses of vapors (Zhang et al., 2014; Krechmer et al., 2016). For the first new case (ROB + ZHAO + TSI), we incorporate IVOC data measured in Pasadena during the CalNex campaign as reported from Zhao et al. (2014). In particular, the measured concentrations of speciated and unspeciated IVOCs and their estimated volatility are used to constrain the initial concentration of these species (as discussed in Sect. 2.2.2 below) as well as to estimate their yields (Zhao 
et al., 2014). Therefore, we replace the inferred concentrations of IVOCs that were used in our previous work and were based on the volatility distribution of Robinson et al. (2007) with concentrations that are directly constrained by measurements. In the ROB + ZHAO + TSI case, the SOA formation parameters used (e.g., yields, oxidation rate constants) are taken from Zhao et al. (2014) for the IVOCs and from Hayes et al. (2015) for the VOCs and SVOCs. Hodzic et al. (2016) have also estimated the IVOC yields while accounting for wall losses using recent laboratory studies. However, the yields reported in that study are for a single lumped species, whereas in our work we estimate the yields using 40 IVOC categories, each representing a single compound or a group of compounds of similar structure and volatility. This method allows a more precise representation of IVOC yields and rate constants in the SOA model.

For the second new case (WOR+ZHAO+TSI), the volatility distribution of P-SVOCs is updated using measurements of POA performed at the Caldecott Tunnel in the California Bay Area (Worton et al., 2014). In the previous two cases described above, the relative volatility distribution of P-SVOCs was taken from the work of Robinson et al. (2007). In this distribution, the relative concentration of SVOCs increases monotonically between the $c^{*}=10^{-2}$ and $10^{2} \mu \mathrm{g} \mathrm{m}^{-3}$ bins. The P-SVOC volatility distribution in the $\mathrm{WOR}+\mathrm{ZHAO}+$ TSI case increases monotonically as well, but the relative concentrations in each bin are different and notably there is a much higher relative concentration of SVOCs in the $c^{*}=10^{2} \mu \mathrm{g} \mathrm{m}^{-3}$ bin (see Fig. 2 and Table S3). In this model case, the updated P-SVOC volatility distribution is only applied to vehicular P-S/IVOCs, whereas the volatility distribution proposed by Robinson et al. (2007) is still used for cooking emissions.

Several recently published papers have found that chamber experiments may underestimate SOA yields due to the loss of semi-volatile vapors to chamber walls (Matsunaga and Ziemann, 2010; Zhang et al., 2014; Krechmer et al., 2016). A sensitivity study has been performed to explore this uncertainty by running the three model cases described above $(\mathrm{ROB}+\mathrm{TSI}, \mathrm{ROB}+\mathrm{ZHAO}+\mathrm{TSI}$, and $\mathrm{WOR}+\mathrm{ZHAO}+\mathrm{TSI})$ with a revised version of the SOA yields for VOCs that account for these wall losses. This revised set of parameters is denoted as MA, whereas the original parameterization for VOC oxidation has been denoted as TSI. A detailed description of how these updated yields were estimated is provided in the Supplement and the values can be found in Table S4. Briefly, equilibrium partitioning is assumed to hold for the organic mass found in the gas phase, particle phase, or chamber walls. The SOA yields are then obtained by refitting SOA chamber yield curves using a model that accounts for partitioning between the three compartments (particle, gas, and wall) and incorporates the equivalent wall mass concentrations published in Krechmer et al. (2016), which are volatility dependent. The SOA chamber yield curves that were refitted were first calculated using the parameters published in
Tsimpidi et al. (2010). There are limits to the assumption that partitioning between the three phases occurs on short enough timescales for all four VOC product volatilities to reach equilibrium during a SOA chamber study. Specifically, at lower volatilities $\left(c^{*} \leq 1 \mu \mathrm{g} \mathrm{m}^{-3}\right)$, the partitioning kinetics of the organic mass from the particles to the chamber walls have an effective timescale of more than an hour, which is similar to or longer than typical chamber experiments (Ye et al., 2016). The limiting step in the partitioning kinetics is evaporation of SVOCs from the particles to the gas phase, and therefore the exact rate of evaporation depends on the OA concentration in the chamber.

Furthermore, as described in the Supplement, the updated SOA yields for VOC oxidation result in distribution of SVOC mass into lower-volatility bins compared to the original parameterization, although the sum for the SVOC yields $\left(\alpha_{i}\right)$ remains similar. In the absence of aging, the SOA yields, $Y$, resulting from the wall-loss correction should be considered upper limits (MA parameterization), whereas the original yields serve as lower limits due to the considerations discussed above (TSI parameterization without aging). As shown in the Supplement (Figs. S1-S7) when aging (TSI parameterization with aging) is included, the SOA yields increase beyond those observed when applying the wall loss correction for most of the VOC classes at longer photochemical ages. It should be noted that SOA masses in Figs. S1-S7 were calculated using the same background as for the other

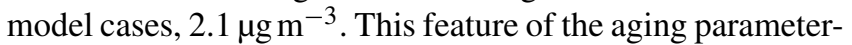
ization is likely to blame for SOA overpredictions observed at long aging times when comparing with ambient data (e.g., Dzepina et al., 2009; Hayes et al., 2015).

According to Krechmer et al. (2016) and other chamber experiments (Matsunaga and Ziemann, 2010), the gas-wall equilibrium timescale does not vary strongly with the chamber size. The timescale for gas-wall equilibrium reported in these previous studies was 7-13 min. Similar timescales have been calculated for a variety of environmental chambers, including chambers that were used to determine many of the yields used in this paper. In addition, Matsunaga and Ziemann (2010) found that partitioning was nearly independent of chamber treatment, reversible, and it obeyed Henry's law. Thus, the effective wall concentrations determined from the chamber experiments reported in Krechmer et al. (2016) are likely applicable to other chambers with different sizes.

The three model cases accounting for wall losses of organic vapors are named $\mathrm{ROB}+\mathrm{MA}, \mathrm{ROB}+\mathrm{ZHAO}+\mathrm{MA}$, and $\mathrm{WOR}+\mathrm{ZHAO}+\mathrm{MA}$. For these cases, the aging of the secondary SVOCs formed from the oxidation of VOCs was not included since multi-generation oxidation is not wellconstrained using data from chamber studies that are run over relatively short timescales (i.e., hours). In addition, aging and correcting for wall losses of organic vapors have been separately proposed to close the gap between observed and predicted SOA concentration from pre-2007 models and are thought to represent the same missing SOA mass. Therefore, 
we run the model with one of these options at a time, as they are conceptually different representations of the same phenomenology. The aging of secondary SVOCs formed from the oxidation of P-IVOCs (and P-SVOCs) has been kept for all of the MA cases, however. To our knowledge, P-IVOC and P-SVOC mechanisms proposed in the literature have always included aging. A similar approach for correcting the yields as described above cannot be applied to P-IVOCs because organics with low volatilities $\left(c^{*}<10 \mu \mathrm{g} \mathrm{m}^{-3}\right)$ will partition to chamber walls very slowly, and SVOCs from P-IVOC oxidation tend to have lower volatilities than the SVOCs formed from VOC oxidation (Tables S1 and S2). Indeed, when trying to refit the VOC and IVOC yield curves, the model assuming equilibrium partitioning between particles, the gas phase, and the walls was able to reproduce the yield curves for VOCs, but not for IVOCs. This difference in the results is consistent with equilibrium not having been reached during the chamber studies on the IVOCs, which produce a greater amount of lower-volatility SVOCs when compared to VOCs during oxidation. These lower-volatility SVOCs have relatively slow evaporation rates from the particles, which prevents the chamber system from reaching equilibrium (Ye et al., 2016).

Simulations of $\mathrm{O}: \mathrm{C}$ have been previously evaluated in Hayes et al. (2015) using laboratory and field data from CalNex to constrain the predicted $\mathrm{O}: \mathrm{C}$. It was concluded in that work that it was not possible to identify one parameterization that performed better than the other parameterizations evaluated because of the lack of constraints on the different parameters used (e.g., oxidation rate constant, oxygen mass in the initial generation of products and that added in later oxidation generations, SOA yields, and emissions). Therefore, incorporating $\mathrm{O}: \mathrm{C}$ predictions into the current box model and using those results in the evaluation discussed here would not provide useful additional constraints.

\subsubsection{IVOC oxidation parameterizations}

An important difference between the ROB + TSI and ROB + MA cases and the other four cases that have been updated with the IVOC measurements of Zhao et al. (2014) is that in the ZHAO cases, the first generation of IVOC oxidation distributes part of the product mass into four different volatility bins $\left(c^{*}=10^{-1}, 1,10^{1}, 10^{2} \mathrm{\mu g} \mathrm{m}^{-3}\right)$ as is displayed in Fig. 2e. This IVOC oxidation scheme is similar to that used for the first step of VOC oxidation (Tsimpidi et al., 2010) as displayed in Fig. 2a and d and has been used to model chamber measurements of SOA from IVOCs (Presto et al., 2010). Contrastingly, in the ROB+TSI and ROB+MA cases, a bin-hopping approach is used for all P-S/IVOCs in which oxidation lowers volatility by only 1 order of magnitude (see Fig. $2 b$ and c). The Robinson et al. (2007) parameters are still used for the formation of SOA from P-SVOCs in the $\mathrm{ROB}+\mathrm{ZHAO}+\mathrm{TSI}$ and $\mathrm{ROB}+\mathrm{ZHAO}+\mathrm{MA}$ cases, but the parameters are only applied to primary emissions in $c^{*}$ bins between $10^{-2}$ and $10^{2} \mu \mathrm{g} \mathrm{m}^{-3}$ inclusive (i.e., the volatilities corresponding to P-SVOCs).

\subsubsection{Determination of initial precursor concentrations}

In the ROB + TSI and ROB + MA cases, the initial concentration of P-S/IVOCs is estimated as follows. The volatility distribution determined by Robinson et al. (2007) is assumed to represent all P-S/IVOCs emitted (Dzepina et al., 2009). The total concentration of P-S/IVOCs is then set so that the amount of P-S/IVOCs in the particle phase is equal to the initial POA concentration. The initial POA concentration is determined from the product of the backgroundsubtracted $\mathrm{CO}$ concentration and the $\triangle \mathrm{POA} / \Delta \mathrm{CO}$ emission ratio (Hayes et al., 2015). While this ratio may change due to evaporation and/or condensation or photochemical oxidation of POA, our previous work (Hayes et al., 2013) has shown that $\triangle \mathrm{POA} / \triangle \mathrm{CO}$ does not change significantly with observed photochemical age at the Pasadena ground site, indicating that the ratio is insensitive to the extent of photochemical oxidation. Furthermore, it was calculated that the ratio would increase by $28 \%$ for an increase in OA concentration from 5 to $15 \mu \mathrm{g} \mathrm{m}^{-3}$, concentrations that are representative of this study. This possible source of error is substantially smaller than current errors suggested for P-S/IVOC emission inventories in 3-D models, in which current schemes are based on scaling POA emission inventories with factors that are not well constrained (Woody et al., 2016). The same method is used for the other four model cases, but only the initial concentration of P-SVOCs is estimated by this method and the initial concentration of P-IVOCs is estimated separately as described in the next paragraph. In addition, in the $\mathrm{WOR}+\mathrm{ZHAO}+\mathrm{TSI}$ and $\mathrm{WOR}+\mathrm{ZHAO}+\mathrm{MA}$ cases the volatility distribution of vehicular P-SVOCs reported in Worton et al. (2014) is used for estimating the initial concentration of vehicular P-SVOCs, whereas the volatility distribution of Robinson et al. (2007) is used for estimating the initial concentration of cooking P-SVOCs.

It should be noted that the tunnel measurements do not include emissions due to cold starts of vehicles. In the box model, only the relative volatility distribution of vehicular POA measured during the tunnel study is used, and thus this potential source of error does not apply to the total amount of vehicular POA emissions in the model. However, it is still possible that the volatility distribution of POA is different during cold starts compared to that of POA emitted from warm-running engines. To our knowledge, measurements of the volatility distribution of POA during cold starts are not available at this time. By comparing the SOA model results using two different POA volatility distributions (Robinson et al., 2007; Worton et al., 2014), we can evaluate to a certain extent the sensitivity of the simulated SOA concentration to the initial POA volatility distribution.

The initial concentrations of VOCs and IVOCs are calculated by multiplying the background-subtracted $\mathrm{CO}$ con- 
centrations measured at Pasadena by the emission ratios $\Delta \mathrm{VOC} / \Delta \mathrm{CO}$ or $\Delta \mathrm{IVOC} / \Delta \mathrm{CO}$. In the ROB $+\mathrm{TSI}$ and ROB + MA cases this method is only applied to the VOCs. The initialization method for the concentrations of the VOCs is the same for all six cases in this paper. For the biogenic VOCs, we follow the same method as Hayes et al. (2015) to determine the initial concentrations since these compounds are not co-emitted with $\mathrm{CO}$. The emission ratios are taken from the literature when available (Warneke et al., 2007; Borbon et al., 2013). For most of the IVOCs and some VOCs, emission ratios are not available in the literature. The ratios are instead determined by performing linear regression analyses on scatter plots of the IVOC or VOC and CO concentrations measured in Pasadena between 00:00 and 06:00 LT when the amount of photochemical aging was very low. During the regression analyses the $x$ intercept was fixed at 105 ppbv CO to account for the background concentration of CO determined in our previous work (Hayes et al., 2013). Thus, the slope of the resulting line corresponds to the estimated emission ratio $(\triangle \mathrm{IVOC} / \triangle \mathrm{CO})$.

It should be noted that the use of emitted VOC-to-CO ratios to estimate VOC emissions does not assume that VOCs are always co-emitted with CO. Rather, it assumes that VOC emission sources are individually small and finely dispersed in an urban area; thus, they are spatially intermingled with the sources of CO. Moreover, previous studies have measured the emission ratios of anthropogenic VOCs with respect to $\mathrm{CO}$ and the results show that vehicle exhaust is a major source of VOC and CO (Warneke et al., 2007; Borbon et al., 2013). Furthermore, the ratios are both temporally and spatially consistent. Thus, when thinking of the entire urban area as a source, the use of emission ratios is justified in this work. As shown in Hayes et al. (2015) in the Supplement, the modeled VOC concentrations are consistent with the measurements, indicating that major VOC sources were not omitted, and the smooth time variations in the VOC concentrations support the use of a global urban source.

\subsection{SOA model}

The VOC yields are taken from Tsimpidi et al. (2010) or determined in this work as described below. The estimation of the IVOC yields (based on values taken from Presto et al., 2010) and of the $\mathrm{OH}$ reaction rate constants for IVOCs follows the same approach used by Zhao et al. (2014). However, instead of using the total SOA yield, $Y$, for a fixed OA concentration as reported in Zhao et al. (2014), we use the SVOC yield, $\alpha$, of each $c^{*}$ bin. It is important to note here that the SOA yields taken from Tsimpidi et al. (2010) and Presto et al. (2010) use a four-product basis set with $c^{*}=10^{0}, 10^{1}, 10^{2}, 10^{3} \mu \mathrm{g} \mathrm{m}{ }^{-3}$ and $c^{*}=10^{-1}$, $10^{0}, 10^{1}, 10^{2} \mu \mathrm{g} \mathrm{m}^{-3}$, respectively. For this box model, it is more appropriate to have a uniform VBS in terms of the bin range utilized; thus, a bin with a lower volatility $\left(c^{*}=10^{-1} \mu \mathrm{g} \mathrm{m}^{-3}\right)$ has been added to the VBS distribution of Tsimpidi et al. (2010). The yield for bin $c^{*}=10^{-1} \mu \mathrm{g} \mathrm{m}{ }^{-3}$ is 0 for VOC oxidation, but when aging occurs mass can be transferred into this bin. However, the change in the total VSOA mass is negligible because for both bins $c^{*}=10^{-1}$ and $10^{0} \mu \mathrm{g} \mathrm{m}^{-3}$ the secondary products almost completely partition to the particle phase.

The $\mathrm{OH}$ reaction rate constants are taken from the literature (Atkinson and Arey, 2003; Carter, 2010) as described previously in Hayes et al. (2015). During aging, the oxidation products undergo subsequent reactions with $\mathrm{OH}$ radicals with a reaction rate constant of $1 \times 10^{-11}$ and $4 \times$ $10^{-11} \mathrm{~cm}^{3} \mathrm{molec}^{-1} \mathrm{~s}^{-1}$ for the products of VOC oxidation and P-S/IVOC oxidation, respectively (Hayes et al., 2015). For each oxidation step during aging, there is a mass increase of $7.5 \%$ due to added oxygen.

The partitioning between gas and particle phases is calculated in each bin by using the reformulation of Pankow theory by Donahue et al. (2006).

$$
x_{\mathrm{p}, i}=\left(1+\frac{C_{i}}{C_{\mathrm{OA}}}\right)^{-1} ; C_{\mathrm{OA}}=\sum_{i}[\mathrm{SVOC}]_{i} x_{\mathrm{p}, i},
$$

in which $\chi_{\mathrm{p}, i}$ is the particle-phase fraction of lumped species $i$ (expressed as a mass fraction), $C_{i}$ is the effective saturation concentration, and $C_{\mathrm{OA}}$ is the total mass of organic aerosol available for partitioning (in micrograms per cubic meter). Only species in the gas phase are allowed to react with $\mathrm{OH}$ radicals in the model, since particle-phase species react at much lower rates (Donahue et al., 2013).

The simulated SOA mass from the model is compared to field measurements of aerosol composition, including results from PMF analysis of aerosol mass spectrometry data (Hayes et al., 2013, 2015). Specifically, the model predictions of urban SOA (i.e., SOA formed within the South Coast Air Basin) are compared to the semi-volatile oxygenated organic aerosol (SV-OOA) concentration from the PMF analysis. The other OA component also attributed to SOA, low-volatility oxygenated organic aerosol (LV-OOA), is primarily from precursors emitted outside the South Coast Air Basin and is used to estimate the background secondary organic aerosol (BG-SOA) as discussed previously (Hayes et al., 2015).

\subsection{Correction for changes in partitioning due to emissions into a shallower boundary layer upwind of Pasadena}

As described in Hayes et al. (2015), during the transport of the pollutants to Pasadena, the planetary boundary layer (PBL) heights increase during the day. Using $\mathrm{CO}$ as a conservative tracer of emissions does not account for how the shallow boundary layer over Los Angeles in the morning influences gas-particle partitioning due to lower vertical mixing and higher absolute POA and SOA concentrations at that time. Thus, as shown in the gas-particle partitioning equation above, there will be a higher partitioning of the species 
to the particle phase and less gas-phase oxidation of primary and secondary SVOCs. Later in the morning and into the afternoon the PBL height increases (Hayes et al., 2013), diluting the POA and urban SOA mass as photochemical ages increase. However, this is a relatively small effect as the partitioning calculation in the SOA model is relatively insensitive to this effect and the absolute OA concentrations (Dzepina et al., 2009; Hayes et al., 2015). Our previous work (Hayes et al., 2015) found in a sensitivity study a $+4 /-12 \%$ variation in predicted urban SOA when various limiting cases were explored for simulation of the PBL (e.g., immediate dilution to the maximum PBL height measured in Pasadena vs. a gradual increase during the morning).

To account for the effect of absolute OA mass on the partitioning calculation, the absolute partitioning mass is corrected using the following method. A PBL height of $345 \mathrm{~m}$ is used for a photochemical age of $0 \mathrm{~h}$ and it reaches a height $855 \mathrm{~m}$ at a photochemical age of $9.2 \mathrm{~h}$, which is the maximum age for the ambient field data. Between the two points, the PBL is assumed to increase linearly. The boundary layer heights are determined using ceilometer measurements from Pasadena at 06:00-09:00 and 12:00-15:00 LT, respectively (Hayes et al., 2013). The second period is chosen because it corresponds to when the maximum photochemical age is observed at the site. The first period is chosen based on transport times calculated for the plume from downtown Los Angeles (Washenfelder et al., 2011) that arrives in Pasadena during the afternoon. There are certain limitations to this correction for the partitioning calculation. First, the correction is based on a conceptual framework in which a plume is emitted and then transported to Pasadena without further addition of POA or SOA precursors. A second limitation is that we do not account for further dilution that may occur as the plume is advected downwind of Pasadena. However, such dilution is not pertinent to the OFR measurements, and thus for photochemical ages beyond ambient levels observed at Pasadena, we focus our analysis on the comparison with the OFR measurements.

\section{Results and discussion}

\subsection{Evolution of SOA concentration over 3 days}

We follow an approach similar to Hayes et al. (2015) in order to analyze the model results. The model SOA concentration is normalized to the background-subtracted $\mathrm{CO}$ concentration to account for dilution, and the ratio is then plotted against photochemical age rather than time to remove variations due to diurnal cycles of precursor and oxidant concentrations. The photochemical age is calculated at a reference $\mathrm{OH}$ radical concentration of $1.5 \times 10^{6} \mathrm{molec} \mathrm{cm}^{-3}$ (DeCarlo et al., 2010). Figure 3 shows this analysis for each model case for up to 3 days of photochemical aging. Since fragmentation and dry deposition are not included in the model, it has only been run to 3 days in order to minimize the importance of these processes with respect to SOA concentrations (Ortega et al., 2016). Nevertheless, it is very likely that gas-phase fragmentation of SVOCs (e.g., branching between functionalization and fragmentation) occurs during oxidative aging over these photochemical ages as is discussed in further detail below.

In each panel of Fig. 3, field measurements are included for comparison. The ambient urban SOA mass at the Pasadena ground site is generally measured under conditions corresponding to photochemical ages of 0.5 days or less (Hayes et al., 2013). The airborne observations of SOA in the Los Angeles basin outflow are also shown as the average of all data between 1 and 2 days of photochemical aging (Bahreini et al., 2012). The gray region on the right serves as an estimate for very aged urban SOA based on data reported by de Gouw and Jimenez (2009). The data from the OFR and a fit of the ambient and reactor data (dotted black line) are also displayed in Fig. 3 (Ortega et al., 2016). In addition, Fig. 4 shows the ratio of modeled-to-measured SOA mass on a logarithmic axis to facilitate evaluation of model performance.

As displayed in the graphs for Fig. 3, it should be noted that the measurements from the OFR (Ortega et al., 2016) and from the NOAA P3 research aircraft (Bahreini et al., 2012) give quite similar results for $\mathrm{SOA} / \triangle \mathrm{CO}$. The OFR measurements are not affected by particle deposition that would occur in the atmosphere on long timescales or at long photochemical ages. Only a few percent of the particles are lost to the walls of the reactor, and this process has been corrected for already in the results of Ortega et al. (2016). The similarity in the two types of observations suggests that ambient particle deposition and plume dispersion do not significantly change the $\mathrm{SOA} / \triangle \mathrm{CO}$ ratio over the photochemical ages analyzed here.

In ROB + TSI, as described in previous work (Hayes et al., 2015), there is a large overprediction of SOA mass at longer photochemical ages. As displayed in Fig. 3, the amount of SOA produced in the model is higher than all of the field measurements taken at a photochemical age longer than 0.5 days. Moreover, the ratios of model to measurement are higher than the upper limit of the gray bar representing the ratios within the measurement uncertainties. There is an agreement with the measurements at moderate photochemical ages (between 0.25 and 0.50 days), but the SOA mass simulated by the model is slightly lower than the measurements at the shortest photochemical ages (less than 0.25 days) even when accounting for measurement uncertainties. In this parameterization, most of the SOA produced comes from the P-S/IVOCs, and uncertainties in the model with respect to these compounds likely explain the overestimation observed at longer photochemical ages. As discussed in the introduction, a major goal in this work is to better constrain the amount of SOA formed from the oxidation of P-S/IVOCs, and the following two model cases $(\mathrm{ROB}+\mathrm{ZHAO}+\mathrm{TSI}$ 

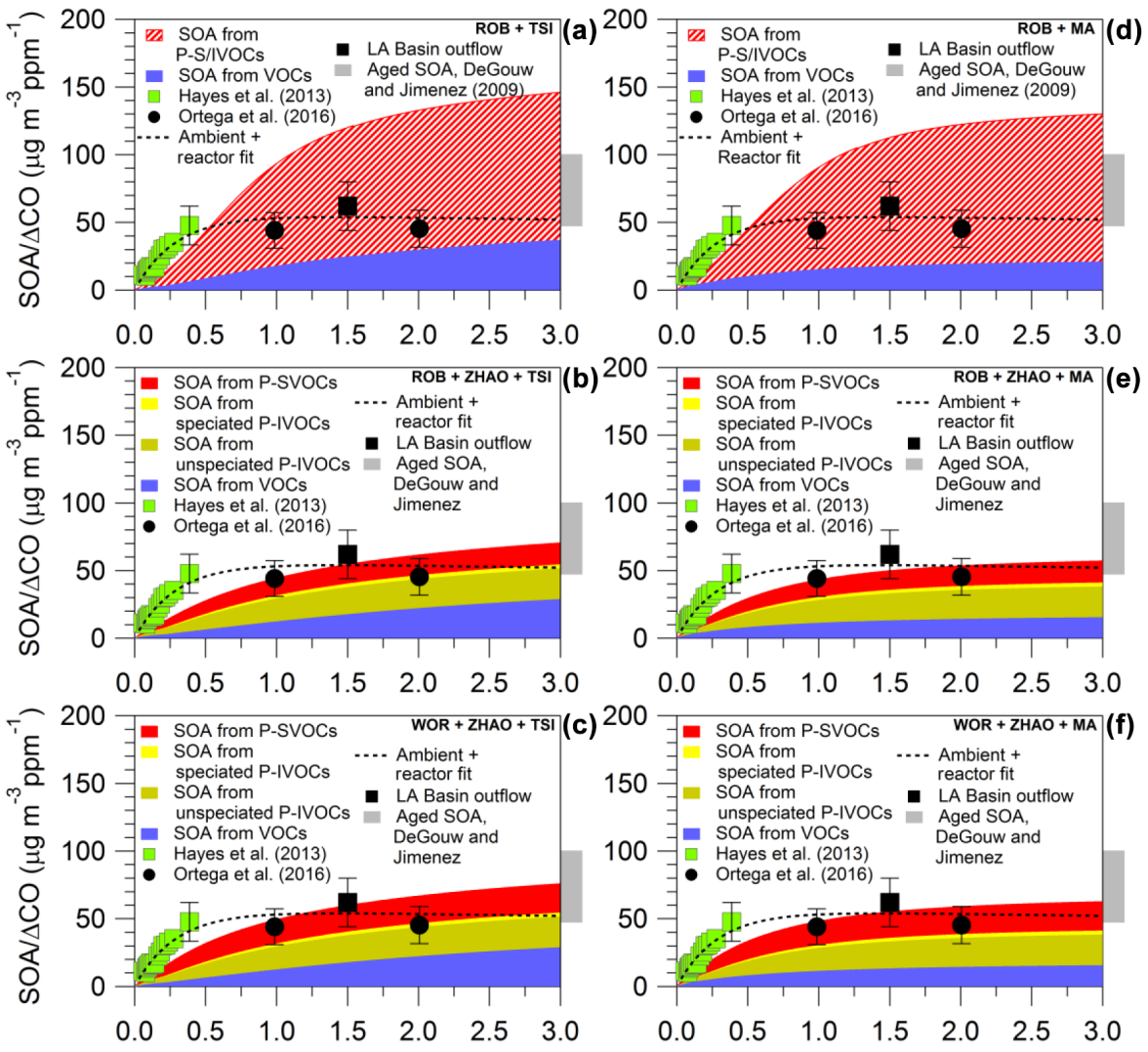

Photochemical age (days)

Figure 3. Predicted urban SOA mass by all six cases for up to 3 days of photochemical aging using a reference OH radical concentration of $1.5 \times 10^{6} \mathrm{molec}^{-3}$. Background SOA is not included in the figure. The SOA concentrations have been normalized to the backgroundsubtracted $\mathrm{CO}(\triangle \mathrm{CO})$ concentration to account for changes in emission strengths and dilution. The SOA/ $\Delta \mathrm{CO}$ data determined from the ambient and OFR measurements at Pasadena as reported by Hayes et al. (2013) (green squares) and Ortega et al. (2016) (black circles) are shown. Also shown is SOA $/ \triangle \mathrm{CO}$ determined from measurements performed aboard the NOAA P3 research aircraft (black square) reported by Bahreini et al. (2012) and highly aged urban air masses (gray bar) reported by de Gouw and Jimenez (2009). The fit for ambient and reactor data reported by Ortega et al. (2016) is also shown (dotted black line).

and WOR + ZHAO + TSI) seek to incorporate new measurements to better constrain the box model with respect to the P-S/IVOCs.

When the yield, rate constants, and initial concentrations of P-IVOCs are constrained using the field measurements reported in Zhao et al. (2014) (ROB + ZHAO + TSI), the SOA mass simulated by the model shows much better agreement with the measurements at longer photochemical ages (Figs. 3 and 4). There is a slight overprediction at 2 days of photochemical aging, but the model is still within the range of measurements of very aged urban SOA reported by De Gouw and Jimenez (2009). The parameterization reported in Robinson et al. (2007) for P-S/IVOCs is based on one study of the photooxidation of diesel emissions from a generator (Robinson et al., 2007). The results obtained here for the betterconstrained $\mathrm{ROB}+\mathrm{ZHAO}+\mathrm{TSI}$ case indicate that the initial concentrations of P-IVOCs as well as the P-IVOC yields within ROB + TSI are too high, which leads to overpre- diction of SOA concentration at longer photochemical ages. Conversely, the SOA mass simulated in ROB + ZHAO + TSI is biased low at shorter photochemical ages (less than 1 day). Similar to other recent studies (Gentner et al., 2012; Hayes et al., 2015; Ortega et al., 2016), there may be unexplained SOA precursors, which rapidly form SOA, not included in the model or yields for fast-reacting species including certain VOCs may be biased low. Both of these possibilities are explored in the other model cases discussed below.

The WOR + ZHAO+ TSI case simulates higher SOA concentrations at shorter photochemical ages compared to the previous case (ROB + ZHAO + TSI), but it is still biased low at shorter photochemical ages. The more rapid SOA formation is due to the updated SVOC volatility distribution in this model case compared to the cases that use the Robinson et al. (2007) distribution. Specifically, as shown in Fig. 2f, there is a higher relative concentration of gas-phase SVOCs in the $c^{*}=10^{2}$ bin and thus a higher ratio of P-SVOC to 

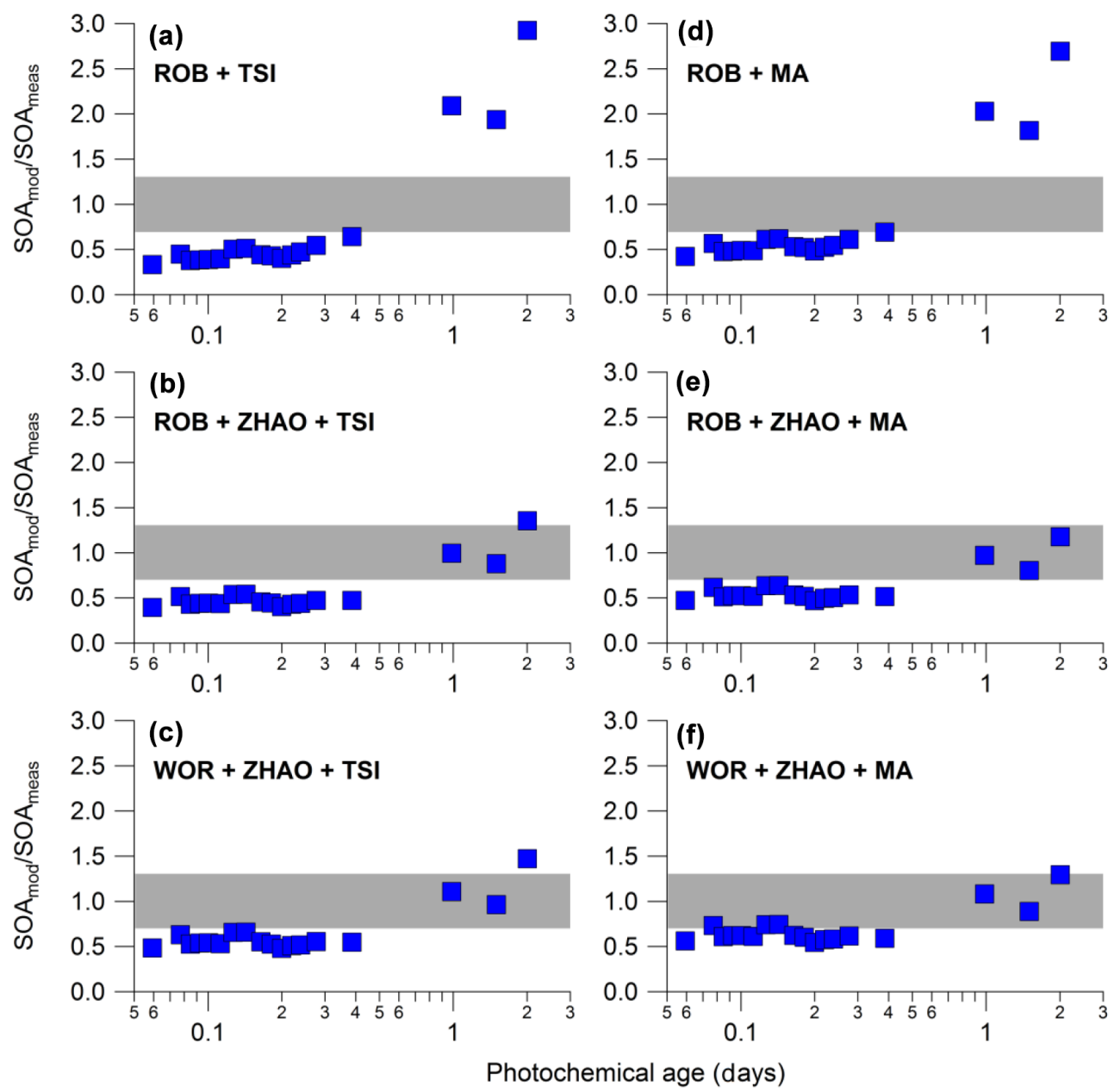

Figure 4. The ratio of the modeled to measured SOA concentrations (blue squares) for all model cases. The measurements are the same as used in Fig. 3. The gray bar indicates ratios that would correspond to model results that are within the estimated $\pm 30 \%$ uncertainty of the measurements.

POA. Given that in the box model (and in most air quality models) the P-SVOC emissions are determined by scaling the POA emissions according to their volatility distribution, a higher P-SVOC-to-POA ratio will then result in a higher initial P-SVOC concentration. Furthermore, SOA formation from P-SVOCs is relatively fast. Together these changes lead to increases in SOA formation during the first hours of photochemical aging when using the Worton et al. (2014) volatility distribution. This case suggests that P-SVOCs in their highest volatility bin $\left(c^{*}=10^{2} \mu \mathrm{g} \mathrm{m}^{-3}\right.$ bin $)$ that are emitted by motor vehicles may be responsible for some of the observed rapid SOA formation within the South Coast Air Basin. When observing the SOA mass simulated at photochemical ages higher than 1 day, the simulation is similar to ROB + ZHAO + TSI. There is better model-measurement agreement than for the ROB + TSI case, but a small overprediction is observed in the comparison to the reactor data at 2 days of photochemical aging.
Also shown in the right-hand panels of Figs. 3 and 4 are the results with the updated yields for the VOCs that account for gas-phase chamber wall losses. For these last three cases $(\mathrm{ROB}+\mathrm{MA}, \mathrm{ROB}+\mathrm{ZHAO}+\mathrm{MA}$, and $\mathrm{WOR}+\mathrm{ZHAO}+\mathrm{MA})$, the rate of SOA formation at short photochemical ages is faster because the secondary SVOC mass from the oxidation of the VOC precursors is distributed into lower-volatility bins compared to the Tsimpidi et al. (2010) parameterization. In the ROB + MA case (Figs. 3d and 4d), similar to ROB + TSI, an overprediction is obtained at longer photochemical ages. There is an improvement in the model at the shortest photochemical ages, but the simulated mass is still lower than the measurements even when considering the measurement uncertainty. Both of these cases perform less well for SOA formation within the South Coast Air Basin, and therefore the remainder of this study is focused on the other four model cases. Overall, the model cases using the updated yields for V-SOA show improvement for the shorter photochemical ages, and the evolution of SOA concentration 
as a function of photochemical age better corresponds to the various measurements taken at Pasadena and from the OFR.

Specifically, the $\mathrm{ROB}+\mathrm{ZHAO}+\mathrm{MA}$ and the WOR + $\mathrm{ZHAO}+\mathrm{MA}$ cases both better represent SOA formation and exhibit better model-measurement agreement among the different cases used in this work. They are both consistent with the OFR reactor data at longer photochemical ages as shown in Figs. 3 and 4 compared with the other cases. At a qualitative level, the MA parameterization simulations are more consistent with the fit of the OFR measurements in which the SOA mass remains nearly constant at longer photochemical ages. In contrast, the cases with the TSI parameterization do not follow this trend as the SOA mass keeps increasing between 2 and 3 days age, which is not observed in the measurements. As already mentioned, the model used for this work does not include fragmentation reactions, and including these reactions, in particular branching between functionalization and fragmentation during gasphase SVOC oxidation, may improve the cases in which this potential update of the TSI parameterization is implemented as discussed below. Figure $4 \mathrm{f}$ indicates that including additional P-SVOC mass in the model and accounting for gas-phase wall losses in chamber studies improves SOA mass concentration simulations with respect to the measurements. However, in the $\mathrm{WOR}+\mathrm{ZHAO}+\mathrm{MA}$ case there is still a slight under-prediction of SOA formed at shorter photochemical ages (between 0.05 and 0.5 days), and this discrepancy is observed in all the other model cases. Given the uncertainties in the model setup discussed in the experimental section, it is not possible to conclude if one of the four cases (i.e., ROB + ZHAO + TSI, WOR + ZHAO + TSI, $\mathrm{ROB}+\mathrm{ZHAO}+\mathrm{MA}$, WOR $+\mathrm{ZHAO}+\mathrm{MA}$ ) more accurately represents $\mathrm{SOA}$ formation in the atmosphere.

According to the OFR data from Ortega et al. (2016), the mass of OA starts to decay due to fragmentation after heterogeneous oxidation at approximately 10 days of photochemical aging. The results are consistent with other OFR field measurements (George and Abbatt, 2010; Hu et al., 2016; Palm et al., 2016). In this work, the model is run only up to 3 days, which is much shorter than the age when heterogeneous oxidation appears to become important. In fact, when including a fragmentation pathway for each of the model cases, a reduction of OA of only $6 \%$ is observed compared to the cases without fragmentation at 3 days of photochemical aging. In this sensitivity study, the fragmentation is parameterized as an exponential decrease in OA concentration that has a lifetime of 50 days following Ortega et al. (2016). Given the results, the inclusion of fragmentation due to heterogeneous oxidation in the model does not significantly change the model results or the conclusions made in this work.

More generally, there are at least three different fragmentation mechanisms that could be responsible for the decrease in SOA formation at very high photochemical ages. The first mechanism is the reaction of oxidants (e.g., $\mathrm{OH}$ ) with the surface of an aerosol particle and decomposition to form products with higher volatility, i.e., due to the heterogeneous oxidation just described. The second type of fragmentation that may be important for very high photochemical ages in the OFR is due to the high concentration of $\mathrm{OH}$ (Palm et al., 2016). Most of the molecules in the gas phase will react multiple times with the available oxidants before having a chance to condense, which will lead to the formation of smaller products too volatile to form SOA. However, this is only important at very high photochemical ages in the OFR, which are not used in this work. A third type of fragmentation can occur during the aging of gas-phase SVOCs (Shrivastava et al., 2013, 2015). The TSI parameterization used in the model from this work and from previous modeling works (Robinson et al., 2007; Hodzic et al., 2010; Shrivastava et al., 2011) only includes the functionalization of the SVOCs and neglects fragmentation reactions. More recently, Shrivastava et al. (2013) modified the VBS approach in a box model by incorporating both pathways and performed several sensitivity studies. The results, when including fragmentation, generally exhibit better agreement with field observations, but as noted in that work the agreement may be fortuitous given that both the emissions as well as the parameters representing oxidation in the model are uncertain. This third type of fragmentation is not simulated in our sensitivity study using the approach above, and it remains poorly characterized due to the complexity of the chemical pathways and the number of compounds contributing to SOA formation as described in Shrivastava et al. (2013).

Despite having higher SOA yields initially, over regional scales (i.e., photochemical ages at and above approximately 2 days) the parameterizations with updated V-SOA yields and without aging produce less SOA because the organic mass in higher volatility bins $\left(c^{*}=100\right.$ and $\left.1000 \mu \mathrm{g} \mathrm{m}^{-3}\right)$ is not further oxidized by aging reactions to produce organics with sufficiently low volatilities to form SOA (Figs. S1-S7). Furthermore, large SOA overpredictions have been shown to occur in gridded 3-D models when using parameterizations with aging that do not include fragmentation reactions (Shrivastava et al., 2015). Fragmentation with aging reactions may still play a role in determining SOA concentrations on such regional scales. However, for the photochemical ages studied here, our results as well as the recent findings regarding gasphase wall losses in chamber studies suggest the inclusion of updated V-SOA yields as well as accurate parameterizations for I-SOA and S-SOA and for the emissions of precursors is more important for accurately predicting urban SOA concentrations.

Finally, Woody et al. (2016) recently proposed a meatcooking volatility distribution and therefore we perform a sensitivity study by using this distribution in our model for P-SVOCs from cooking sources. The results are displayed in the Supplement (Fig. S8), in which this alternate approach has been implemented for the WOR + ZHAO+TSI and $\mathrm{WOR}+\mathrm{ZHAO}+\mathrm{MA}$ cases. By comparing the results ob- 
tained from this sensitivity study with Fig. 3, the two cases in the sensitivity study display a slight decrease in $\mathrm{SOA} / \Delta \mathrm{CO}$ values over 3 days of photochemical aging with a difference of approximately $9 \%$ at 3 days. Thus, the modelmeasurement comparison does not change significantly relative to the base case. Given the similarities between the sensitivity study and Fig. 3, as well as the possibility of cooking SOA sources other than meat cooking (i.e., heated cooking oils; Liu et al., 2017), the remainder of our work uses the Robinson et al. (2007) volatility distribution for P-SVOCs from cooking sources.

\subsubsection{SOA concentration estimated at Pasadena: fossil and non-fossil fractions}

In panel (a) of Fig. 5, the box model is compared against the urban SOA determined by PMF analysis of the AMS measurements at Pasadena (Hayes et al., 2013). In panel (b) of the same figure the model is compared against the fossil and non-fossil fraction of urban SOA as obtained from ${ }^{14} \mathrm{C}$ measurements reported in Zotter et al. (2014). Both panels show measurements and predictions corresponding to 12:0015:00 LT, when SOA concentrations peaked due to longer photochemical ages ( $5 \mathrm{~h}$ on average) as well as the arrival of emissions transported from source-rich western regions of the South Coast Air Basin.

Similar to the results in Figs. 3 and 4 for short photochemical ages, the SOA mass simulated by the ROB + ZHAO+TSI case is biased low in Fig. 5a. The ROB + ZHAO + MA, $\mathrm{WOR}+\mathrm{ZHAO}+\mathrm{TSI}$, and $\mathrm{WOR}+\mathrm{ZHAO}+\mathrm{MA}$ cases show better model-measurement agreement as the simulated SOA mass is within the measurement uncertainty or essentially equal to the lower limit of the concentration that is defined by the measurement uncertainty. Figure 5a also allows evaluation of the contribution of each precursor type to the SOA at Pasadena. For the four cases displayed, the P-SVOCs and PIVOCs are responsible for 70-83\% of the urban SOA formation. Thus, more than half of the urban SOA is attributed to these precursors even in the MA parameterizations in which the model is run with the updated yields, which doubles VSOA compared to the cases using the yields reported from Tsimpidi et al. (2010). Furthermore, 8-27\% of the measured urban SOA is due to V-SOA in which the range of values is due to the uncertainty in the measurements as well as the difference in simulated V-SOA concentration for each case.

According to the ${ }^{14} \mathrm{C}$ measurements, an average of $71 \pm$ $3 \%$ of urban SOA at Pasadena is fossil carbon, which is thought to be due to the importance of vehicular emissions, especially during the morning rush hour (Bahreini et al., 2012; Zotter et al., 2014; Hayes et al., 2015). In general, the box model gives results consistent with the ${ }^{14} \mathrm{C}$ measurements. To make this comparison, the simulated SOA is apportioned between fossil S-SOA, fossil I-SOA, fossil VSOA, cooking S-SOA, and biogenic V-SOA. The last two apportionments correspond to non-fossil carbon. This eval-
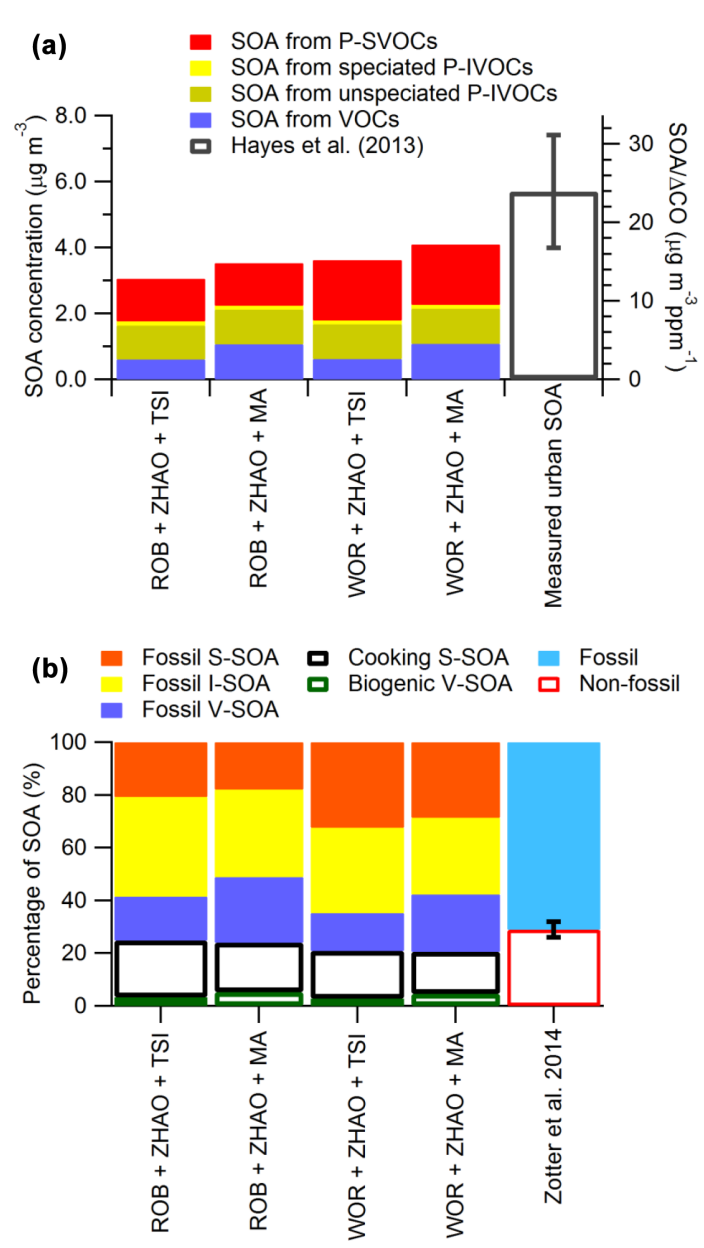

Figure 5. (a) Predicted and measured urban SOA mass for 12:0015:00 LT at the Pasadena ground site. (b) The fractional mass of fossil S-SOA, fossil I-SOA, and fossil V-SOA, as well as cooking S-SOA and biogenic V-SOA for the same time and location. The percentage of urban SOA from fossil and non-fossil sources as reported in Zotter et al. (2014) is also displayed. The fossil sources are shown as solid bars and the non-fossil sources as hollow bars.

uation is possible following an approach similar to Hayes et al. (2015) in which the identity of the precursor is used to apportion SOA. Briefly, the fossil S-SOA is formed from P-SVOCs emitted with hydrocarbon-like OA (HOA), which is a surrogate for vehicular POA. Second, cooking S-SOA is formed from P-SVOCs emitted with cooking-influenced OA (CIOA). The concentrations of HOA and CIOA were determined previously using PMF analysis. Fossil V-SOA is formed from aromatics, alkanes, and olefins while isoprene and terpenes are responsible for biogenic V-SOA. The treatment of IVOCs in the comparison with the ${ }^{14} \mathrm{C}$ measurements has been updated from our 2015 study. Previously, it was assumed that P-IVOCs were co-emitted with CIOA, but the recent work of Zhao et al. (2014) and others indicates that petroleum sources contribute substantially to IVOC emissions (Dunmore et al., 2015; Ots et al., 2016). Therefore, 
the IVOCs are considered entirely fossil carbon in order to obtain the results shown in Fig. 5b.

As seen in Fig. 5b, for all the model cases, cooking SSOA dominates the non-fossil fraction and biogenic VOCs have only a small contribution to non-fossil urban SOA. This result is consistent with our previous work and indicates that agreement between the model and ${ }^{14} \mathrm{C}$ measurements cannot be achieved without including an urban source of non-fossil carbon such as P-SVOCs from cooking. With respect to fossil SOA, more S-SOA is formed when using the volatility distribution of vehicular POA reported from Worton et al. (2014) due to the greater proportion of gas phase of P-SVOCs. When the V-SOA yields are updated in the model (MA parameterizations), there is a corresponding increase in both fossil and non-fossil V-SOA.

When comparing the fossil and non-fossil carbon split, all the cases are either in agreement with the measurement within its uncertainty or slightly lower. Starting with the $\mathrm{ROB}+\mathrm{ZHAO}+\mathrm{TSI}$ case, the fossil fraction increases from 75 to $79 \%$ in each case as VOCs or P-SVOCs from vehicle emissions have greater importance for SOA formation. While the uncertainties reported in Zotter et al. (2014) were $71 \pm 3 \%$, there are likely additional errors due to different factors that may influence the model or measurements. For example, a portion of the P-IVOCs may be from cooking sources rather than entirely from fossil sources as is assumed above (Klein et al., 2016). Taking the WOR + ZHAO + MA case as an example, since it is the best performing case in this work according to Fig. 5a, model-measurement agreement is obtained within measurement uncertainties if one assumes that $19-39 \%$ of P-IVOCs come from cooking emissions. U1timately, the differences observed in the comparison with the ${ }^{14} \mathrm{C}$ data are very likely smaller than these errors discussed here, and it is concluded that all the model cases perform equally well with respect to the fossil-non-fossil carbon split.

As reported in Gentner et al. (2012), emissions from petroleum-derived fuels such as diesel and gasoline have an important contribution to the formation of SOA. However, there have been conflicting results regarding the relative contributions of diesel vs. gasoline emissions (Bahreini et al., 2012; Gentner et al., 2012). In this work, the relative contribution of different SOA sources is estimated following a procedure similar to that previously published in Hayes et al. (2015), and the results are shown in Fig. S9. Briefly, the source apportionment method follows four steps. First, after classifying the SOA mass from isoprene and terpenes as biogenic V-SOA, the remaining V-SOA is attributed to gasoline emissions since the diesel contribution to V-SOA is small ( $\sim 3 \%$ ) (Hayes et al., 2015). Second, for the diesel and gasoline contribution to S-SOA, $70( \pm 10) \%$ of HOA is emitted from diesel vehicles with the remainder from gasoline vehicles (Hayes et al., 2013), and thus it is assumed for the source apportionment that $70 \%(30 \%)$ of vehicular PSVOCs is from diesel (gasoline) vehicles. Third, the S-SOA from cooking sources is calculated separately in the model, in which the initial concentration of cooking P-SVOCs is estimated using the measured CIOA concentration and the method described in Sect. 2.2.2 above. Lastly, the fractional contributions to I-SOA mass are difficult to determine since there are still uncertainties about the sources of IVOCs. According to Zhao et al. (2014), petroleum sources other than on-road vehicles likely contribute substantially to primary IVOCs, but evidence exists that cooking may be a source of IVOCs as well (Klein et al., 2016). Thus, while we attribute I-SOA to these two sources, we do not distinguish the sources. The estimated source apportionment in Fig. S9 attributes urban SOA as follows: $4 \%$ to biogenic V-SOA, $22 \%$ to gasoline V-SOA, $9 \%$ to gasoline S-SOA, $20 \%$ to diesel S-SOA, and $16 \%$ to cooking S-SOA. The remaining $29 \%$ is I-SOA that is either due to cooking or off-road emissions of P-IVOCs.

It should be noted that according to McDonald et al. (2015), the emissions from vehicles have decreased over time (i.e., between 1970 and 2010) due to regulations in California. Warneke et al. (2012) also observed that the emission ratios of some SOA precursors (i.e., $\Delta \mathrm{VOC} / \Delta \mathrm{CO}$ ) remained constant between 2002 and 2010, while absolute concentrations decreased. Conversely, cooking and off-road emissions are subject to different regulations in California, and the ratios of cooking or off-road emissions to vehicular emissions have likely changed with time, which means that the source apportionment results for urban SOA presented here will be specific to 2010 .

\subsection{SOA formation vs. precursor oxidation rate constant}

Recent results from Ortega et al. (2016) point to the importance of fast-reacting precursors for urban SOA during CalNex, and we can use their results to further evaluate our box model. The fraction of SOA formed from each precursor class as a function of the precursor rate constant is displayed in Fig. 6. The right axis of Fig. 6 shows the correlation $\left(R^{2}\right)$ of different VOCs with the maximum concentration of SOA formed using the OFR as a function of their oxidation rate constants as reported in Ortega et al. (2016). This analysis of the OFR data allows us to constrain the rate constants of the most important SOA precursors. A detailed description of how the $R^{2}$ values were obtained can be found in Ortega et al. (2016). According to the $R^{2}$ data, the VOC compounds that correlate best with maximum SOA formation potential are those that have $\log k_{\mathrm{OH}}$ rate constants ranging from -10.5 to -10.0 . When comparing the percentage of SOA mass simulated by the model with the observed $R^{2}$ values, all of the four cases are not entirely consistent with the $R^{2}$ data. According to the model, more SOA mass is formed from precursors in the bin ranging from -11.0 to -10.5 (the majority of mass formed comes from P-IVOCs) rather than the bin ranging from -10.5 to -10.0 . In contrast, the $R^{2}$ value is higher for the more reactive bin. If either fast-reacting pre- 
cursors were missing in the model or if the rate constants of the currently implemented precursors were too small, then correcting either error would shift the relative distribution shown in Fig. 6 towards faster-reacting SOA precursors. In turn, the trend in the percentage of modeled SOA mass may more closely follow the trend in $R^{2}$ values.

\subsection{Volatility distribution of OA}

Based on the evaluations carried out up to this point on the six model cases, the WOR+ZHAO+MA case seems to most closely reproduce the observations. Thus, the entire volatility distribution of the OA, precursors, and secondary gas-phase organics is analyzed for this model case. Figure 7 shows this distribution for three selected photochemical ages: 0,5 , and $36 \mathrm{~h}$. The figure allows us to track the evolution of SOA and secondary gas-phase organics from each precursor class in terms of their concentration and volatility and also to evaluate the reduction of precursor concentrations. For the results, the volatility distribution of all organics resolved by precursor class, except for the VOCs and P-IVOCs, can be taken directly from the model. To determine the volatility distribution of the VOCs and P-IVOCs, the SIMPOL.1 method (Pankow and Asher, 2008) is used to estimate the effective saturation concentration of each compound or lumped species in the model. Also included in Fig. 7, in the bottom-right panel, is the observed volatility distribution for the Pasadena ground site, which is an average of measurements collected during 12:00-15:00 LT and corresponds to $5 \mathrm{~h}$ of photochemical aging. For the measurements, the volatility distribution of VOCs was determined using gas chromatography mass spectrometry (GC-MS) data (Borbon et al., 2013), whereas the IVOC distribution is taken from Zhao et al. (2014). The volatility distribution of SVOCs was determined using combined thermal denuder AMS measurements (see the Supplement for further details).

For the volatility distribution of the model at time 0 , the concentrations of P-SVOCs and P-IVOCs monotonically increase with the value of $c^{*}$. However, a discontinuity in the mass concentration exists between the $c^{*}=10^{2}$ and $10^{3} \mathrm{\mu g} \mathrm{m}^{-3}$ bins. This discontinuity can be explained by several factors. First, the measured IVOC mass concentration in the $c^{*}=10^{3} \mathrm{\mu g} \mathrm{m}^{-3}$ bin is very low, and since the initial concentrations of IVOCs in the model are constrained by the field measurements, the model will also have very low concentrations. Zhao et al. (2014) already noted that the concentration of P-IVOCs in this bin is relatively low when compared to the volatility distribution from Robinson et al. (2007). Another possible explanation is the presence of cooking sources, which in the model are responsible for substantial P-SVOC mass $(\sim 50 \%)$ but may have a smaller contribution to the P-IVOC mass.

During oxidation the volatility distribution evolves and the concentration of secondary organics increases in the bins between $c^{*}=10^{-1}$ and $10^{3} \mu \mathrm{g} \mathrm{m}^{-3}$ (inclusive), and the largest portion of SOA is found in the $c^{*}=1 \mu \mathrm{g} \mathrm{m}^{-3}$ bin. This result is due to the partitioning of the organic mass to the particle phase and the lack of particle-phase reactions in the model, which leads to very slow oxidation rates for species found in the lower-volatility bins. After $36 \mathrm{~h}$, a large portion of the precursors have been reacted, although some primary and secondary material remains in the gas phase, giving rise to more gradual SOA formation.

In Fig. 7, it is possible to compare the measured volatility distribution with the model simulation at $5 \mathrm{~h}$ of photochemical aging. It should be noted that the relatively high concentrations of VOCs in the model compared to the measurements are due to the model containing VOCs for which measurements were not obtained in Pasadena. There are 47 VOCs used in the model and only 19 VOCs were measured. However, the remaining VOCs have been measured in other urban locations (Warneke et al., 2007; Borbon et al., 2013) and thus it is assumed they are also present in the South Coast Air Basin. For this work, we include these 28 remaining VOCs by assuming that they are also emitted in the South Coast Air Basin with identical emission ratios $(\Delta \mathrm{VOC} / \Delta \mathrm{CO})$. When comparing only measured and modeled VOCs (shown in hollow black bars), the results are consistent $\left(3.1,3.6\right.$, and $2.2 \mu \mathrm{g} \mathrm{m}^{-3}$ from $c^{*}=10^{7}$ to $10^{9} \mu \mathrm{g} \mathrm{m}^{-3}$ bins vs. 3.8, 3.7, and $2.2 \mu \mathrm{g} \mathrm{m}^{-3}$ for the measurements). Conversely, the model appears to have a low bias for the concentrations of P-IVOCs $\left(0.16,0.63,0.89\right.$, and $2.3 \mu \mathrm{g} \mathrm{m}^{-3}$ from $c^{*}=10^{3}$ to $10^{6} \mu \mathrm{g} \mathrm{m}^{-3}$ bins vs. $0.21,1.39,2.65$, and $3.82 \mu \mathrm{g} \mathrm{m}^{-3}$ for the measurements). This low bias is seen for each volatility bin and could possibly be explained by either oxidation rate constants that are too high or $\Delta \mathrm{IVOC} / \Delta \mathrm{CO}$ ratios that are too low. The latter explanation seems more likely given that the rate constants estimated using surrogate compounds and structure-activity relationships for the unspeciated P-IVOCs are generally lower limits (Zhao et al., 2014), which would result in a high bias rather than a low bias. The $\triangle \mathrm{IVOC} / \triangle \mathrm{CO}$ ratios may be low because the photochemical age between 00:00 and 6:00 LT is not strictly zero, and some oxidation may have occurred during the period used to determine the ratio values. Emission ratios such as $\triangle \mathrm{IVOC} / \triangle \mathrm{CO}$ facilitate incorporating P-IVOC emissions into 3-D models that already use $\mathrm{CO}$ emissions inventories, and the $\triangle \mathrm{IVOC} / \triangle \mathrm{CO}$ ratios reported here could be used for this purpose. However, the resulting I-SOA concentrations should be considered lower limits given that the emission ratios, and also the rate constants, are likely themselves lower limits.

To further explore the impact of potential errors in the initial IVOC concentrations, a sensitivity study has been carried out using initial concentrations calculated based on the observed photochemical age and measured IVOC concentrations at Pasadena as well as the estimated IVOC oxidation rate constants (Zhao et al., 2014). This alternate approach is implemented for the ROB +ZHAO+MA and WOR + ZHAO + MA cases and does not use nighttime IVOC-to-CO ratios. 

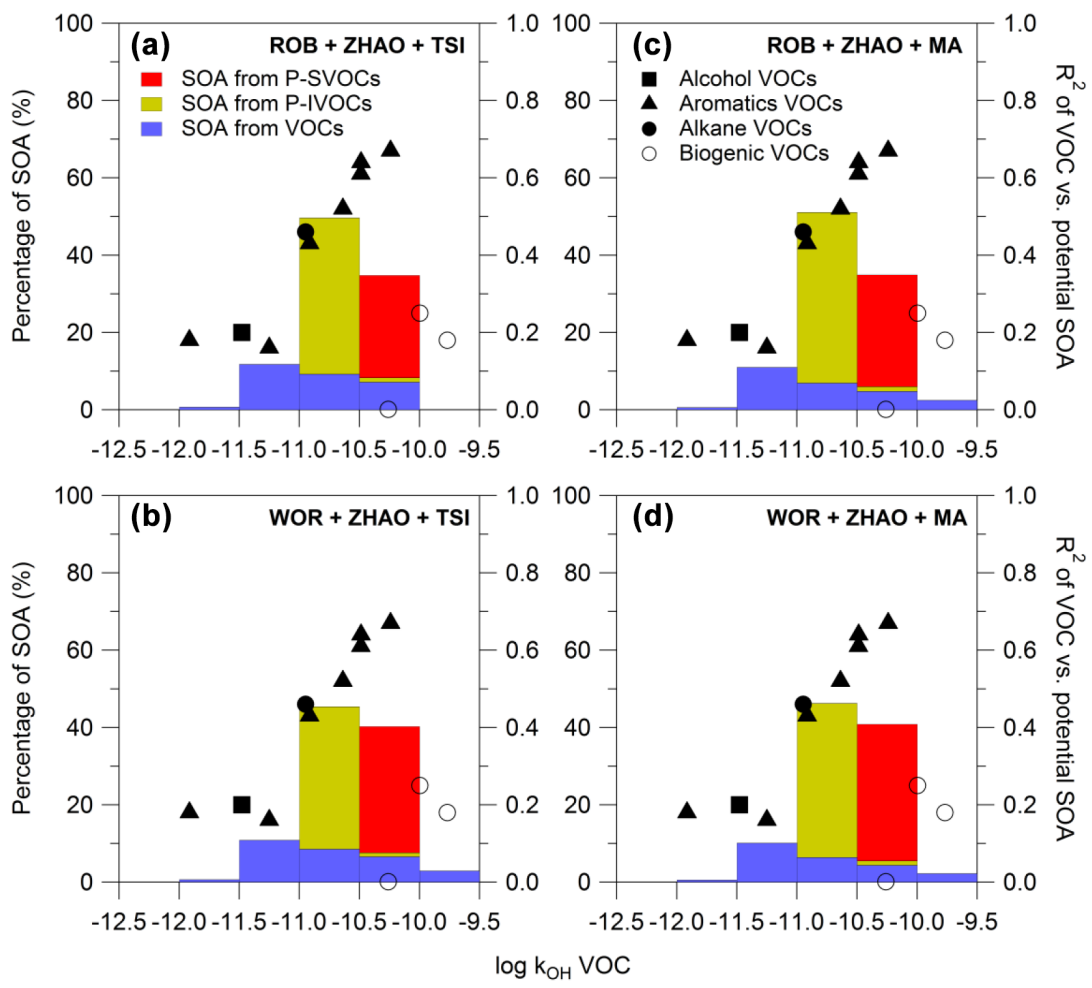

Figure 6. Percentage of SOA mass formed from different precursors at 1.5 days of photochemical aging $\left(\right.$ at $\left.1.5 \times 10^{6} \mathrm{molec} \mathrm{OH}^{-3}\right)$ binned according to precursor rate constant. The correlations $\left(R^{2}\right)$ between the concentrations of different VOCs and the maximum SOA concentration formed in the OFR as reported by Ortega et al. (2016) are represented by the markers. The shape of the marker indicates the chemical family to which each compound belongs. For the VOCs and the P-IVOCs the rate constant is the constant for the initial oxidation reaction. The measurements of IVOCs used here allow the rate constants of these precursors to be taken from published work or estimated using structure-activity relationships as described previously (Zhao et al., 2014). For S-SOA, the rate constant is the aging rate constant reported originally by Robinson et al. (2007).

The results when using this alternative approach are shown in the Supplement (Fig. S10). When comparing Fig. S10 with Fig. 3, differences are minor. The model-measurement agreement improves slightly at shorter photochemical ages (less than 1 day). At the same time a slightly larger overprediction is observed at longer photochemical ages. However, the formation of SOA modeled in this sensitivity test is similar to the original cases from Fig. 3 with an average difference of only $21 \%$, which represents a relatively small error compared to other uncertainties in SOA modeling. The IVOC initial concentrations used in this sensitivity test are slightly higher than those calculated using the IVOC-to-CO ratio, which explains the small increase in modeled SOA/ $\Delta \mathrm{CO}$. Ultimately, the different approaches for determining the initial IVOC concentration in the model are reasonably consistent, and both approaches perform similarly given the model and measurement uncertainties.

For the measurements of SVOCs, all the mass in bins lower than $10^{-2} \mu \mathrm{g} \mathrm{m}^{-3}$ are lumped into this bin for Fig. 7 since the model does not contain lower-volatility bins. In addition, the $10^{1}$ and $10^{2} \mu \mathrm{g} \mathrm{m}^{-3}$ bins are not well-resolved because the thermal denuder did not consistently reach temper- atures low enough (less than $37^{\circ} \mathrm{C}$ ) to resolve SVOCs in this range of volatilities. Thus, the $10^{1} \mu \mathrm{g} \mathrm{m}^{-3}$ bin may contain some higher-volatility particulate mass although this contribution is expected to be small due to the low particle-phase fraction of compounds in the $10^{2} \mu \mathrm{g} \mathrm{m}^{-3} \mathrm{bin}$. With these considerations in mind, the volatility distribution of the SVOCs is somewhat different in the model compared to the measurements. Most notably, the model does not form a significant amount of lower-volatility SOA in the $10^{-2} \mu \mathrm{g} \mathrm{m}^{-3}$ bin, whereas the measurements have much higher concentrations in this bin. A factor that may explain this difference between the volatility distributions is the lack of particle-phase reactions that continue to transform SOA into lower-volatility products, a process which is not considered in the model. One example of a particle-phase reaction is the formation of SOA within deliquesced particles, including the partitioning of glyoxal to the aqueous phase to produce oligomers as discussed in Ervens and Volkamer (2010), although that specific mechanism was of little significance during CalNex (Washenfelder et al., 2011; Knote et al., 2014). Alternatively, the use of an aging parameterization in which the volatility may decrease by more than 1 order of magnitude 

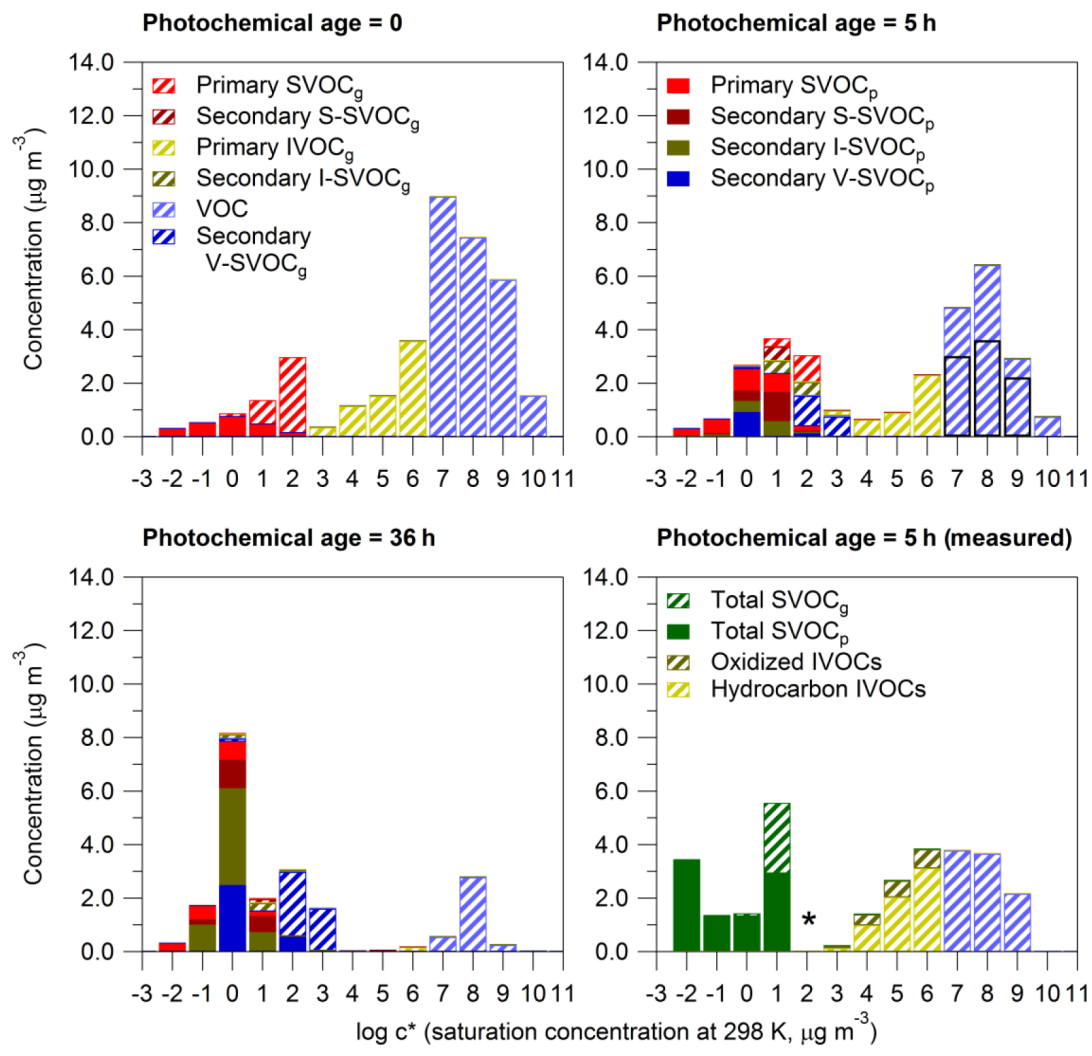

Figure 7. OA volatility distribution as simulated by the WOR $+\mathrm{ZHAO}+\mathrm{MA}$ case displayed at different photochemical ages $(0,5$, and $36 \mathrm{~h})$. The partitioning of the species is indicated using patterned bars for gas-phase mass and solid bars for particle-phase mass. The bottomright graph also shows the measured volatility distribution of OA. The SVOC volatility distribution is determined using a combined thermal denuder AMS system as described in the Supplement. The IVOC volatility distribution was previously published in Zhao et al. (2014), and the VOC distribution was determined from GC-MS measurements using the SIMPOL.1 model to estimate the volatility of each VOC. The asterisk in the bin $\log c^{*}=2$ indicates that measurements are not available for this bin. It should be noted that not all the VOCs in the model were measured at Pasadena (see text for details). For direct visual comparison with the measurements, the simulated concentrations of only the VOCs measured at Pasadena are indicated by the black hollow bars in the bins $\log c^{*}=7,8$, and $9 \mu \mathrm{g} \mathrm{m}^{-3}$.

per oxidation reaction would also distribute some SOA mass into lower $c^{*}$ bins. Hayes et al. (2015) previously evaluated different parameters for aging. However, the results from this previous study showed that substantial overprediction of SOA was observed when using the Grieshop et al. (2009) parameterization in which each oxidation reaction reduced volatility by 2 orders of magnitude. New parameterizations may be necessary to produce the observed SOA volatility and concentration simultaneously (Cappa and Wilson, 2012). However, we note that the additional low-volatility organic mass will not significantly change SOA predictions in urban regions where OA concentrations are relatively high. When comparing the total amount of particle-phase SVOCs, it seems that the model reproduces the measurements reasonably well ( $\left.6.2 \mathrm{vs.} 9.0 \mu \mathrm{g} \mathrm{m}^{-3}\right)$ as expected based on the comparisons of the total SOA concentration discussed above. In addition, the total concentration of SVOCs (particle and gas phase) is similar ( $\left.11.2 \mathrm{vs.} 11.8 \mu \mathrm{g} \mathrm{m}^{-3}\right)$, although it is difficult to determine the gas-phase concentration of SVOCs in the $10^{2} \mu \mathrm{g} \mathrm{m}^{-3}$ bin from measurements due to the lack of particle mass in this bin under ambient concentrations as well as the limited temperature range of the thermal denuder system.

Recently, Woody et al. (2016) published a paper that modeled SOA over California using the Environmental Protection Agency's Community Multiscale Air Quality Model that had been updated to include a VBS treatment of SOA (CMAQVBS). As discussed in that paper, the modeled P-S/IVOC emission inventories remain an important source of uncertainty in 3-D grid-based models. In that previous study several different ratios of P-S/IVOC-to-POA emissions were evaluated against measurements, and it was found that a ratio of 7.5 gave the best agreement between the CMAQ-VBS model and observations. From the results shown in Fig. 7 at a photochemical age of $0 \mathrm{~h}$, a P-S/IVOC-to-POA ratio of 5.2 is calculated. This ratio is different from that determined by Woody et al. (2016), and may be biased low due to possibly low $\triangle \mathrm{IVOC} / \triangle \mathrm{CO}$ emission ratios as discussed earlier in this section, but it both serves as a useful lower bound and has the 
advantage of being determined from empirical measurements of aerosols rather than by tuning a model to match measured SOA concentrations. As stated in Woody et al. (2016), the higher ratio may compensate for other missing (or underrepresented) formation pathways in SOA models or excessive dispersion of SOA in their model.

\section{Conclusions}

We have used several data sets from recently published papers to better constrain and evaluate urban SOA formation pathways and precursors, especially P-SVOCs and P-IVOCs, within a custom-built box model. The use of the box model facilitates the incorporation of these new data sets as well as the evaluation of a number of model cases. All the model cases are able to correctly simulate the fossil vs. non-fossil carbon split at the Pasadena ground site, providing support for the performance of the model. When measurements of IVOCs are used to constrain the concentrations of P-IVOCs, such as in the $\mathrm{ROB}+\mathrm{ZHAO}+\mathrm{TSI}$ and $\mathrm{ROB}+\mathrm{ZHAO}+\mathrm{MA}$ cases, a large improvement of the model at longer photochemical age is observed. However, these model cases are still biased low at shorter photochemical ages. By additionally constraining the P-SVOCs with measurements of those precursors, such as in the WOR $+\mathrm{ZHAO}+\mathrm{TSI}$ case, better model-measurement agreement is obtained at shorter photochemical ages, yet the model is still biased low. Finally, the $\mathrm{WOR}+\mathrm{ZHAO}+\mathrm{MA}$ case, which incorporates state-ofthe-art measurements of P-SVOCs and P-IVOCs and also accounts for the effect of chamber wall losses on VOC yields, obtains model-measurement agreement within measurement uncertainties at long photochemical ages. However, it also displays a low bias at short photochemical ages, which is similar to the $\mathrm{ROB}+\mathrm{ZHAO}+\mathrm{MA}$ case. This bias may be due to low $\triangle \mathrm{IVOC} / \triangle \mathrm{CO}$ emissions ratios or IVOC oxidation rate constants for which the estimated values are too low. It is also possible that additional sources or SOA formation pathways are missing from the model. Moreover, a P-S/IVOCto-POA ratio of 5.2 is determined, which can be combined with POA emission inventories to constrain the emissions of $\mathrm{P}-\mathrm{S} / \mathrm{IVOCs}$ in gridded chemical transport models.

In addition to evaluating the model performance with respect to SOA concentration, the rates of SOA formation are compared against measurements as well. This aspect of the study was enhanced by the use of OFR data to constrain SOA formation potential for up to 3 days of photochemical aging (at $1.5 \times 10^{6}$ molec $\mathrm{OH} \mathrm{cm}^{-3}$ ). The model cases that include multi-generation oxidative aging predict substantial SOA increases after 1.5 days of aging, which is not consistent with the OFR measurements. In contrast, model cases in which aging is omitted and instead SOA yields for VOCs are corrected for gas-phase wall losses in chamber experiments predict little change in the SOA concentration after 1.5 days. These results highlight the uncertainties associated with ag- ing schemes for SOA that come from VOCs, which are often implemented in SOA models. Instead, implementing corrected yields for VOCs results in similar amounts of SOA but formation rates vs. time that are more consistent with observations.

Therefore, the model cases with updated VOC yields that account for chamber wall losses best reproduce the ambient and OFR data. However, while the $\mathrm{WOR}+\mathrm{ZHAO}+\mathrm{MA}$ case appears to represent a slight improvement over the ROB + $\mathrm{ZHAO}+\mathrm{MA}$ case, as well as over the $\mathrm{ROB}+\mathrm{ZHAO}+\mathrm{TSI}$ and WOR + ZHAO+ TSI cases, it is not possible to conclude that one set of parameters is better than the other since the difference in the predictions for these four cases $(15 \%$ on average) is likely smaller than the uncertainties due to the model setup as well as the lack of a gas-phase fragmentation pathway during aging. Moreover, uncertainties in the yields corrected for vapor wall loss remain, and the correction of the yields has been performed here using data from a limited number of laboratory studies. In particular, the effect of temperature and humidity on gas-wall partitioning needs to be characterized. The results obtained in our work motivate future studies by showing that SOA models using wall-losscorrected yields reproduce observations for a range of photochemical ages at a level of accuracy that is as good as or better than parameterizations with the uncorrected yields.

In all six of the model cases, a large majority of the urban SOA at Pasadena is the result of P-SVOC and P-IVOC oxidation. While this result alone cannot be taken as conclusive due to the uncertainties in the model parameters, further evidence for the importance of P-SVOCs and P-IVOCs is obtained by analyzing the percentage of SOA formed at long photochemical ages ( $\sim 1.5$ days $)$ as a function of the precursor rate constant. The P-SVOCs and P-IVOCs have rate constants that are similar to highly reactive VOCs that have been previously found to strongly correlate with SOA formation potential measured by the OFR.

Lastly, the modeled volatility distribution of the total (gas and particle phase) organic mass between $c^{*}=10^{-2}$ and $10^{10} \mathrm{gg} \mathrm{m}^{-3}$ is analyzed at three ages and compared against volatility-resolved measurements. While the total concentrations of gas- and particle-phase SVOCs are reasonably well simulated, there are still important differences between the measured and modeled volatility distribution of SVOCs. These differences highlight the need for further studies of the chemical pathways that may give rise to SOA in lowvolatility bins at $c^{*}=10^{-2} \mu \mathrm{g} \mathrm{m}^{-3}$ and lower.

Data availability. The measurement data were collected during the 2010 CalNex ground campaign in Pasadena and are open to the public at the NOAA website https://esrl.noaa.gov/csd/groups/ csd7/measurements/2010calnex/Ground/DataDownload/ (NOAA, 2016). The model code is accessible by contacting the corresponding authors. 


\section{The Supplement related to this article is available online at https://doi.org/10.5194/acp-17-9237-2017-supplement.}

Competing interests. The authors declare that they have no conflict of interest.

Acknowledgements. This work was partially supported by a Natural Science and Engineering Research Council of Canada (NSERC) Discovery Grant (RGPIN/05002-2014), le Fonds de recherche Nature et technologies (FRQNT) du Québec (2016-PR-192364), and the Université de Montréal. AMO and JLJ were supported by CARB 11-305 and EPA STAR 83587701-0. This paper has not been reviewed by the EPA and thus no endorsement should be inferred. We gratefully acknowledge VOC data provided by Joost de Gouw and Jessica B. Gilman.

Edited by: Gordon McFiggans

Reviewed by: two anonymous referees

\section{References}

Ahmadov, R., McKeen, S. A., Robinson, A. L., Bahreini, R., Middlebrook, A. M., de Gouw, J. A., Meagher, J., Hsie, E. Y., Edgerton, E., Shaw, S., and Trainer, M.: A volatility basis set model for summertime secondary organic aerosols over the eastern United States in 2006, J. Geophys. Res.-Atmos., 117, D06301, https://doi.org/10.1029/2011JD016831, 2012.

Atkinson, R. and Arey, J.: Atmospheric degradation of volatile organic compounds, Chem. Rev., 103, 4605-4638, 2003.

Bahreini, R., Middlebrook, A. M., de Gouw, J. A., Warneke, C., Trainer, M., Brock, C. A., Stark, H., Brown, S. S., Dube, W. P., Gilman, J. B., Hall, K., Holloway, J. S., Kuster, W. C., Perring, A. E., Prévôt, A. S. H., Schwarz, J. P., Spackman, J. R., Szidat, S., Wagner, N. L., Weber, R. J., Zotter, P., and Parrish, D. D.: Gasoline emissions dominate over diesel in formation of secondary organic aerosol mass, Geophys. Res. Lett., 39, https://doi.org/10.1029/2011GL050718, L06805, 2012.

Borbon, A., Gilman, J. B., Kuster, W. C., Grand, N., Chevaillier, S., Colomb, A., Dolgorouky, C., Gros, V., Lopez, M., SardaEsteve, R., Holloway, J., Stutz, J., Petetin, H., McKeen, S., Beekmann, M., Warneke, C., Parrish, D. D., and de Gouw, J. A.: Emission ratios of anthropogenic volatile organic compounds in northern mid-latitude megacities: observations vs. emission inventories in Los Angeles and Paris, J. Geophys. Res.-Atmos., 118, 2041-2057, 2013.

Cappa, C. D. and Wilson, K. R.: Multi-generation gas-phase oxidation, equilibrium partitioning, and the formation and evolution of secondary organic aerosol, Atmos. Chem. Phys., 12, 9505-9528, https://doi.org/10.5194/acp-12-9505-2012, 2012.

Carter, W. P. L.: Development of the SAPRC-07 chemical mechanism, Atmos. Environ., 44, 5324-5335, 2010.

Chan, A. W. H., Kautzman, K. E., Chhabra, P. S., Surratt, J. D., Chan, M. N., Crounse, J. D., Kürten, A., Wennberg, P. O., Flagan, R. C., and Seinfeld, J. H.: Secondary organic aerosol formation from photooxidation of naphthalene and alkylnaphthalenes: implications for oxidation of intermediate volatility organic compounds (IVOCs), Atmos. Chem. Phys., 9, 3049-3060, https://doi.org/10.5194/acp-9-3049-2009, 2009.

Christensen, J. H., Krishna Kumar, K., Aldrian, E., An, S.-I., Cavalcanti, I. F. A., de Castro, M., Dong, W., Goswami, A., Hall, A., Kanyanga, J. K., Kitoh, A., Kossin, J., Lau, N.-C., Renwick, J., Stephenson, D. B., Xie, S.-P., and Zhou, T.: Climate change 2013: the physical scientific basis, Contribution of Working Group I to the Fifth Assessment Report of the Intergovernmental Panel on Climate Change, 2013.

De Gouw, J. and Jimenez, J. L.: Organic aerosols in the Earth's atmosphere, Environ. Sci. Technol., 43, 7614-7618, 2009.

DeCarlo, P. F., Ulbrich, I. M., Crounse, J., de Foy, B., Dunlea, E. J., Aiken, A. C., Knapp, D., Weinheimer, A. J., Campos, T., Wennberg, P. O., and Jimenez, J. L.: Investigation of the sources and processing of organic aerosol over the Central Mexican Plateau from aircraft measurements during MILAGRO, Atmos. Chem. Phys., 10, 5257-5280, https://doi.org/10.5194/acp10-5257-2010, 2010.

Dockery, D. W. and Pope, C. A.: Acute respiratory effects of particulate air-pollution, Annu. Rev. Publ. Health, 15, 107-132, 1994.

Donahue, N. M., Robinson, A. L., Stanier, C. O., and Pandis, S. N.: Coupled partitioning, dilution, and chemical aging of semivolatile organics, Environ. Sci. Technol., 40, 2635-2643, 2006.

Donahue, N. M., Chuang, W., Epstein, S. A., Kroll, J. H., Worsnop, D. R., Robinson, A. L., Adams, P. J., and Pandis, S. N.: Why do organic aerosols exist? Understanding aerosol lifetimes using the two-dimensional volatility basis set, Environ. Chem., 10, 151-157, 2013.

Dunmore, R. E., Hopkins, J. R., Lidster, R. T., Lee, J. D., Evans, M. J., Rickard, A. R., Lewis, A. C., and Hamilton, J. F.: Diesel-related hydrocarbons can dominate gas phase reactive carbon in megacities, Atmos. Chem. Phys., 15, 9983-9996, https://doi.org/10.5194/acp-15-9983-2015, 2015.

Dzepina, K., Volkamer, R. M., Madronich, S., Tulet, P., Ulbrich, I. M., Zhang, Q., Cappa, C. D., Ziemann, P. J., and Jimenez, J. L.: Evaluation of recently-proposed secondary organic aerosol models for a case study in Mexico City, Atmos. Chem. Phys., 9, 5681-5709, https://doi.org/10.5194/acp-9-5681-2009, 2009.

Dzepina, K. Cappa, C. D., Volkamer, R. M., Madronich, S., DeCarlo, P. F., Zaveri, R. A., and Jimenez, J. L.: Modeling the multiday evolution and aging of secondary organic aerosol during MILAGRO 2006, Environ. Sci. Technol., 45, 3496-3503, 2011.

Ervens, B. and Volkamer, R.: Glyoxal processing by aerosol multiphase chemistry: towards a kinetic modeling framework of secondary organic aerosol formation in aqueous particles, Atmos. Chem. Phys., 10, 8219-8244, https://doi.org/10.5194/acp10-8219-2010, 2010.

Fountoukis, C., Megaritis, A. G., Skyllakou, K., Charalampidis, P. E., Denier van der Gon, H. A. C., Crippa, M., Prévôt, A. S. H., Fachinger, F., Wiedensohler, A., Pilinis, C., and Pandis, S. N.: Simulating the formation of carbonaceous aerosol in a European Megacity (Paris) during the MEGAPOLI summer and winter campaigns, Atmos. Chem. Phys., 16, 3727-3741, https://doi.org/10.5194/acp-16-3727-2016, 2016.

Gentner, D. R., Isaacman, G., Worton, D. R., Chan, A. W. H., Dallmann, T. R., Davis, L., Liu, S., Day, D. A., Russell, L. M., Wil- 
son, K. R., Weber, R. J., Guha, A., Harley, R. A., and Goldstein, A. H.: Elucidating secondary organic aerosol from diesel and gasoline vehicles through detailed characterization of organic carbon emissions, P. Natl. Acad. Sci. USA, 109, 1831818323, 2012.

George, I. J. and Abbatt, J. P. D.: Heterogeneous oxidation of atmospheric aerosol particles by gas-phase radicals, Nat. Chem., 2, 713-722, 2010.

Grieshop, A. P., Logue, J. M., Donahue, N. M., and Robinson, A. L.: Laboratory investigation of photochemical oxidation of organic aerosol from wood fires 1: measurement and simulation of organic aerosol evolution, Atmos. Chem. Phys., 9, 1263-1277, https://doi.org/10.5194/acp-9-1263-2009, 2009.

Hallquist, M., Wenger, J. C., Baltensperger, U., Rudich, Y., Simpson, D., Claeys, M., Dommen, J., Donahue, N. M., George, C., Goldstein, A. H., Hamilton, J. F., Herrmann, H., Hoffmann, T., Iinuma, Y., Jang, M., Jenkin, M. E., Jimenez, J. L., Kiendler-Scharr, A., Maenhaut, W., McFiggans, G., Mentel, Th. F., Monod, A., Prévôt, A. S. H., Seinfeld, J. H., Surratt, J. D., Szmigielski, R., and Wildt, J.: The formation, properties and impact of secondary organic aerosol: current and emerging issues, Atmos. Chem. Phys., 9, 5155-5236, https://doi.org/10.5194/acp9-5155-2009, 2009.

Hayes, P. L., Ortega, A. M., Cubison, M. J., Froyd, K. D., Zhao, Y., Cliff, S. S., Hu, W. W., Toohey, D. W., Flynn, J. H., Lefer, B. L., Grossberg, N., Alvarez, S., Rappenglueck, B., Taylor, J. W., Allan, J. D., Holloway, J. S., Gilman, J. B., Kuster, W. C., De Gouw, J. A., Massoli, P., Zhang, X., Liu, J., Weber, R. J., Corrigan, A. L., Russell, L. M., Isaacman, G., Worton, D. R., Kreisberg, N. M., Goldstein, A. H., Thalman, R., Waxman, E. M., Volkamer, R., Lin, Y. H., Surratt, J. D., Kleindienst, T. E., Offenberg, J. H., Dusanter, S., Griffith, S., Stevens, P. S., Brioude, J., Angevine, W. M., and Jimenez, J. L.: Organic aerosol composition and sources in Pasadena, California, during the 2010 CalNex campaign, J. Geophys. Res.-Atmos., 118, 9233-9257, 2013.

Hayes, P. L., Carlton, A. G., Baker, K. R., Ahmadov, R., Washenfelder, R. A., Alvarez, S., Rappenglück, B., Gilman, J. B., Kuster, W. C., de Gouw, J. A., Zotter, P., Prévôt, A. S. H., Szidat, S., Kleindienst, T. E., Offenberg, J. H., Ma, P. K., and Jimenez, J. L.: Modeling the formation and aging of secondary organic aerosols in Los Angeles during CalNex 2010, Atmos. Chem. Phys., 15, 5773-5801, https://doi.org/10.5194/acp-15-5773-2015, 2015.

Heald, C. L., Coe, H., Jimenez, J. L., Weber, R. J., Bahreini, R., Middlebrook, A. M., Russell, L. M., Jolleys, M., Fu, T.-M., Allan, J. D., Bower, K. N., Capes, G., Crosier, J., Morgan, W. T., Robinson, N. H., Williams, P. I., Cubison, M. J., DeCarlo, P. F., and Dunlea, E. J.: Exploring the vertical profile of atmospheric organic aerosol: comparing 17 aircraft field campaigns with a global model, Atmos. Chem. Phys., 11, 12673-12696, https://doi.org/10.5194/acp-11-12673-2011, 2011.

Hodzic, A. and Jimenez, J. L.: Modeling anthropogenically controlled secondary organic aerosols in a megacity: a simplified framework for global and climate models, Geosci. Model Dev., 4, 901-917, https://doi.org/10.5194/gmd-4-901-2011, 2011.

Hodzic, A., Jimenez, J. L., Madronich, S., Canagaratna, M. R., DeCarlo, P. F., Kleinman, L., and Fast, J.: Modeling organic aerosols in a megacity: potential contribution of semi-volatile and intermediate volatility primary organic compounds to secondary or- ganic aerosol formation, Atmos. Chem. Phys., 10, 5491-5514, https://doi.org/10.5194/acp-10-5491-2010, 2010.

Hodzic, A., Kasibhatla, P. S., Jo, D. S., Cappa, C. D., Jimenez, J. L., Madronich, S., and Park, R. J.: Rethinking the global secondary organic aerosol (SOA) budget: stronger production, faster removal, shorter lifetime, Atmos. Chem. Phys., 16, 7917-7941, https://doi.org/10.5194/acp-16-7917-2016, 2016.

Hu, W., Palm, B. B., Day, D. A., Campuzano-Jost, P., Krechmer, J. E., Peng, Z., de Sá, S. S., Martin, S. T., Alexander, M. L., Baumann, K., Hacker, L., Kiendler-Scharr, A., Koss, A. R., de Gouw, J. A., Goldstein, A. H., Seco, R., Sjostedt, S. J., Park, J. H., Guenther, A. B., Kim, S., Canonaco, F., Prévôt, A. S. H., Brune, W. H., and Jimenez, J. L.: Volatility and lifetime against $\mathrm{OH}$ heterogeneous reaction of ambient isoprene-epoxydiolsderived secondary organic aerosol (IEPOX-SOA), Atmos. Chem. Phys., 16, 11563-11580, https://doi.org/10.5194/acp-16-115632016, 2016.

Jimenez, J. L., Canagaratna, M. R., Donahue, N. M., Prévôt, A. S. H., Zhang, Q., Kroll, J. H., DeCarlo, P. F., Allan, J. D., Coe, H., Ng, N. L., Aiken, A. C., Docherty, K. S., Ulbrich, I. M., Grieshop, A. P., Robinson, A. L., Duplissy, J., Smith, J. D., Wilson, K. R., Lanz, V. A., Hueglin, C., Sun, Y. L., Tian, J., Laaksonen, A., Raatikainen, T., Rautiainen, J., Vaattovaara, P., Ehn, M., Kulmala, M., Tomlinson, J. M., Collins, D. R., Cubison, M. J., Dunlea, E. J., Huffman, J. A., Onasch, T. B., Alfarra, M. R., Williams, P. I., Bower, K., Kondo, Y., Schneider, J., Drewnick, F., Borrmann, S., Weimer, S., Demerjian, K., Salcedo, D., Cottrell, L., Griffin, R., Takami, A., Miyoshi, T., Hatakeyama, S., Shimono, A., Sun, J. Y., Zhang, Y. M., Dzepina, K., Kimmel, J. R., Sueper, D., Jayne, J. T., Herndon, S. C., Trimborn, A. M., Williams, L. R., Wood, E. C., Middlebrook, A. M., Kolb, C. E., Baltensperger, U., and Worsnop, D. R.: Evolution of organic aerosols in the atmosphere, Science, 326, 1525-1529, 2009.

Klein, F., Platt, S. M., Farren, N. J., Detournay, A., Bruns, E. A., Bozzetti, C., Daellenbach, K. R., Kilic, D., Kumar, N. K., Pieber, S. M., Slowik, J. G., Temime-Roussel, B., Marchand, N., Hamilton, J. F., Baltensperger, U., Prévôt, A. S. H., and El Haddad, I.: Characterization of gas-phase organics using proton transfer reaction time-of-flight mass spectrometry: cooking emissions, Environ. Sci. Technol., 50, 1243-1250, 2016.

Knote, C., Hodzic, A., Jimenez, J. L., Volkamer, R., Orlando, J. J., Baidar, S., Brioude, J., Fast, J., Gentner, D. R., Goldstein, A. H., Hayes, P. L., Knighton, W. B., Oetjen, H., Setyan, A., Stark, H., Thalman, R., Tyndall, G., Washenfelder, R., Waxman, E., and Zhang, Q.: Simulation of semi-explicit mechanisms of SOA formation from glyoxal in aerosol in a 3-D model, Atmos. Chem. Phys., 14, 6213-6239, https://doi.org/10.5194/acp14-6213-2014, 2014.

Krechmer, J. E., Pagonis, D., Ziemann, P. J., and Jimenez, J. L.: Quantification of gas-wall partitioning in teflon environmental chambers using rapid bursts of low-volatility oxidized species generated in situ, Environ. Sci. Technol., 50, 5757-5765, 2016.

Kroll, J. H., Ng, N. L., Murphy, S. M., Flagan, R. C., and Seinfeld, J. H.: Secondary organic aerosol formation from isoprene photooxidation, Environ. Sci. Technol., 40, 1869-1877, 2006.

Liu, T., Li, Z., Chan, M., and Chan, C. K.: Formation of secondary organic aerosols from gas-phase emissions of 
heated cooking oils, Atmos. Chem. Phys., 17, 7333-7344, https://doi.org/10.5194/acp-17-7333-2017, 2017.

Matsunaga, A. and Ziemann, P. J.: Gas-Wall partitioning of organic compounds in a teflon film chamber and potential effects on reaction product and aerosol yield measurements, Aerosol Sci. Tech., 44, 881-892, 2010.

McDonald, B. C., Goldstein, A. H., and Harley, R. A.: Long-term trends in California mobile source emissions and ambient concentrations of black carbon and organic aerosol, Environ. Sci. Technol., 49, 5178-5188, 2015.

Ng, N. L., Kroll, J. H., Chan, A. W. H., Chhabra, P. S., Flagan, R. C., and Seinfeld, J. H.: Secondary organic aerosol formation from $m$-xylene, toluene, and benzene, Atmos. Chem. Phys., 7, 3909-3922, https://doi.org/10.5194/acp-7-3909-2007, 2007.

NOAA: The 2010 CalNex LA ground site data, available at: https://esrl.noaa.gov/csd/groups/csd7/measurements/ 2010calnex/Ground/DataDownload/ (last access: 26 July 2017), 2016.

Odum, J. R., Hoffmann, T., Bowman, F., Collins, D., Flagan, R. C., and Seinfeld, J. H.: Gas/particle partitioning and secondary organic aerosol yields, Environ. Sci. Technol., 30, 2580-2585, 1996.

Ortega, A. M., Hayes, P. L., Peng, Z., Palm, B. B., Hu, W., Day, D. A., Li, R., Cubison, M. J., Brune, W. H., Graus, M., Warneke, C., Gilman, J. B., Kuster, W. C., de Gouw, J., GutiérrezMontes, C., and Jimenez, J. L.: Real-time measurements of secondary organic aerosol formation and aging from ambient air in an oxidation flow reactor in the Los Angeles area, Atmos. Chem. Phys., 16, 7411-7433, https://doi.org/10.5194/acp16-7411-2016, 2016.

Ots, R., Young, D. E., Vieno, M., Xu, L., Dunmore, R. E., Allan, J. D., Coe, H., Williams, L. R., Herndon, S. C., Ng, N. L., Hamilton, J. F., Bergström, R., Di Marco, C., Nemitz, E., Mackenzie, I. A., Kuenen, J. J. P., Green, D. C., Reis, S., and Heal, M. R.: Simulating secondary organic aerosol from missing diesel-related intermediate-volatility organic compound emissions during the Clean Air for London (ClearfLo) campaign, Atmos. Chem. Phys., 16, 6453-6473, https://doi.org/10.5194/acp16-6453-2016, 2016.

Palm, B. B., Campuzano-Jost, P., Ortega, A. M., Day, D. A., Kaser, L., Jud, W., Karl, T., Hansel, A., Hunter, J. F., Cross, E. S., Kroll, J. H., Peng, Z., Brune, W. H., and Jimenez, J. L.: In situ secondary organic aerosol formation from ambient pine forest air using an oxidation flow reactor, Atmos. Chem. Phys., 16, 29432970, https://doi.org/10.5194/acp-16-2943-2016, 2016.

Pankow, J. F.: An absorption model of the gas aerosol partitionning incolved in the formation of secondary organic aerosol, Atmos. Environ., 28, 189-193, 1994.

Pankow, J. F. and Asher, W. E.: SIMPOL.1: a simple group contribution method for predicting vapor pressures and enthalpies of vaporization of multifunctional organic compounds, Atmos. Chem. Phys., 8, 2773-2796, https://doi.org/10.5194/acp-8-27732008, 2008.

Parrish, D. D., Stohl, A., Forster, C., Atlas, E. L., Blake, D. R., Goldan, P. D., Kuster, W. C., and de Gouw, J. A.: Effects of mixing on evolution of hydrocarbon ratios in the troposphere, J. Geophys. Res.-Atmos., 112, L17811, https://doi.org/10.1029/2006GL026899, 2007.
Presto, A. A., Miracolo, M. A., Donahue, N. M., and Robinson, A. L.: Secondary organic aerosol formation from high- $\mathrm{NO}_{x}$ photo-oxidation of low volatility precursors: $n$-Alkanes, Environ. Sci. Technol., 44, 2029-2034, 2010.

Robinson, A. L., Donahue, N. M., Shrivastava, M. K., Weitkamp, E. A., Sage, A. M., Grieshop, A. P., Lane, T. E., Pierce, J. R., and Pandis, S. N.: Rethinking organic aerosols: semivolatile emissions and photochemical aging, Science, 315, 1259-1262, 2007.

Ryerson, T. B., Andrews, A. E., Angevine, W. M., Bates, T. S., Brock, C. A., Cairns, B., Cohen, R. C., Cooper, O. R., de Gouw, J. A., Fehsenfeld, F. C., Ferrare, R. A., Fischer, M. L., Flagan, R. C., Goldstein, A. H., Hair, J. W., Hardesty, R. M., Hostetler, C. A., Jimenez, J. L., Langford, A. O., McCauley, E., McKeen, S. A., Molina, L. T., Nenes, A., Oltmans, S. J., Parrish, D. D., Pederson, J. R., Pierce, R. B., Prather, K., Quinn, P. K., Seinfeld, J. H., Senff, C. J., Sorooshian, A., Stutz, J., Surratt, J. D., Trainer, M., Volkamer, R., Williams, E. J., and Wofsy, S. C.: The 2010 California research at the Nexus of Air Quality and Climate Change (CalNex) field study, J. Geophys. Res.-Atmos., 118, 5830-5866, 2013.

Shrivastava, M., Fast, J., Easter, R., Gustafson Jr., W. I., Zaveri, R. A., Jimenez, J. L., Saide, P., and Hodzic, A.: Modeling organic aerosols in a megacity: comparison of simple and complex representations of the volatility basis set approach, Atmos. Chem. Phys., 11, 6639-6662, https://doi.org/10.5194/acp11-6639-2011, 2011.

Shrivastava, M., Zelenyuk, A., Imre, D., Easter, R., Beranek, J., Zaveri, R. A., and Fast, J.: Implications of low volatility SOA and gas-phase fragmentation reactions on SOA loadings and their spatial and temporal evolution in the atmosphere, J. Geophys. Res.-Atmos., 118, 3328-3342, 2013.

Shrivastava, M., Easter, R. C., Liu, X. H., Zelenyuk, A., Singh, B., Zhang, K., Ma, P. L., Chand, D., Ghan, S., Jimenez, J. L., Zhang, Q., Fast, J., Rasch, P. J., and Tiitta, P.: Global transformation and fate of SOA: implications of low-volatility SOA and gas-phase fragmentation reactions, J. Geophys. Res.-Atmos., 120, 4169-4195, 2015.

Spracklen, D. V., Jimenez, J. L., Carslaw, K. S., Worsnop, D. R., Evans, M. J., Mann, G. W., Zhang, Q., Canagaratna, M. R., Allan, J., Coe, H., McFiggans, G., Rap, A., and Forster, P.: Aerosol mass spectrometer constraint on the global secondary organic aerosol budget, Atmos. Chem. Phys., 11, 12109-12136, https://doi.org/10.5194/acp-11-12109-2011, 2011.

Tsimpidi, A. P., Karydis, V. A., Zavala, M., Lei, W., Molina, L., Ulbrich, I. M., Jimenez, J. L., and Pandis, S. N.: Evaluation of the volatility basis-set approach for the simulation of organic aerosol formation in the Mexico City metropolitan area, Atmos. Chem. Phys., 10, 525-546, https://doi.org/10.5194/acp-10-5252010, 2010.

Volkamer, R., Jimenez, J. L., San Martini, F., Dzepina, K., Zhang, Q., Salcedo, D., Molina, L. T., Worsnop, D. R., and Molina, M. J.: Secondary organic aerosol formation from anthropogenic air pollution: rapid and higher than expected, Geophys. Res. Lett., 33, L17811, https://doi.org/10.1029/2006GL026899, 2006.

Warneke, C., McKeen, S. A., de Gouw, J. A., Goldan, P. D., Kuster, W. C., Holloway, J. S., Williams, E. J., Lerner, B. M., Parrish, D. D., Trainer, M., Fehsenfeld, F. C., Kato, S., At- 
las, E. L., Baker, A., and Blake, D. R.: Determination of urban volatile organic compound emission ratios and comparison with an emissions database, J. Geophys. Res.-Atmos., 112, D10s47, https://doi.org/10.1029/2006JD007930, 2007.

Warneke, C., de Gouw, J. A., Holloway, J. S., Peischl, J., Ryerson, T. B., Atlas, E., Blake, D., Trainer, M., and Parrish, D. D.: Multiyear trends in volatile organic compounds in Los Angeles, California: five decades of decreasing emissions, J. Geophys. Res.-Atmos., 117, D00V17, https://doi.org/10.1029/2012JD017899, 2012.

Washenfelder, R. A., Young, C. J., Brown, S. S., Angevine, W. M., Atlas, E. L., Blake, D. R., Bon, D. M., Cubison, M. J., de Gouw, J. A., Dusanter, S., Flynn, J., Gilman, J. B., Graus, M., Griffith, S., Grossberg, N., Hayes, P. L., Jimenez, J. L., Kuster, W. C., Lefer, B. L., Pollack, I. B., Ryerson, T. B., Stark, H., Stevens, P. S., and Trainer, M. K.: The glyoxal budget and its contribution to organic aerosol for Los Angeles, California, during CalNex 2010, J. Geophys. Res.-Atmos., 116, D00V02, https://doi.org/10.1029/2011JD016314, 2011.

Watson, J. G.: Visibility: science and regulation, J. Air Waste Manage., 52, 628-713, 2002.

Woody, M. C., Baker, K. R., Hayes, P. L., Jimenez, J. L., Koo, B., and Pye, H. O. T.: Understanding sources of organic aerosol during CalNex-2010 using the CMAQ-VBS, Atmos. Chem. Phys., 16, 4081-4100, https://doi.org/10.5194/acp16-4081-2016, 2016.

Worton, D. R., Isaacman, G., Gentner, D. R., Dallmann, T. R., Chan, A. W. H., Ruehl, C., Kirchstetter, T. W., Wilson, K. R., Harley, R. A., and Goldstein, A. H.: Lubricating oil dominates primary organic aerosol emissions from motor vehicles, Environ. Sci. Technol., 48, 3698-3706, 2014.

Ye, P., Ding, X., Hakala, J., Hofbauer, V., Robinson, E. S., and Donahue, N. M.: Vapor wall loss of semi-volatile organic compounds in a teflon chamber, Aerosol Sci. Tech., 50, 822-834, 2016.
Yuan, B., Veres, P. R., Warneke, C., Roberts, J. M., Gilman, J. B., Koss, A., Edwards, P. M., Graus, M., Kuster, W. C., Li, S.-M., Wild, R. J., Brown, S. S., Dubé, W. P., Lerner, B. M., Williams, E. J., Johnson, J. E., Quinn, P. K., Bates, T. S., Lefer, B., Hayes, P. L., Jimenez, J. L., Weber, R. J., Zamora, R., Ervens, B., Millet, D. B., Rappenglück, B., and de Gouw, J. A.: Investigation of secondary formation of formic acid: urban environment vs. oil and gas producing region, Atmos. Chem. Phys., 15, 1975-1993, https://doi.org/10.5194/acp-15-1975-2015, 2015.

Zhang, Q., Jimenez, J. L., Canagaratna, M. R., Allan, J. D., Coe, H., Ulbrich, I., Alfarra, M. R., Takami, A., Middlebrook, A. M., Sun, Y. L., Dzepina, K., Dunlea, E., Docherty, K., DeCarlo, P. F., Salcedo, D. Onasch, T., Jayne, J. T., Miyoshi, T., Shimono, A., Hatakeyama, S., Takegawa, N., Kondo, Y., Schneider, J., Drewnick, F., Borrmann, S., Weimer, S., Demerjian, K., Williams, P., Bower, K., Bahreini, R., Cottrell, L., Griffin, R. J., Rautiainen, J., Sun, J. Y., Zhang, Y. M., and Worsnop, D. R.: Ubiquity and dominance of oxygenated species in organic aerosols in anthropogenically-influenced Northern Hemisphere midlatitudes, Geophys. Res. Lett., 34, L13801, https://doi.org/10.1029/2007GL029979, 2007.

Zhang, X., Cappa, C. D., Jathar, S. H., McVay, R. C., Ensberg, J. J., Kleeman, M.1 J., and Seinfeld, J. H.: Influence of vapor wall loss in laboratory chambers on yields of secondary organic aerosol, $\mathrm{P}$. Natl. Acad. Sci. USA, 111, 5802-5807, 2014.

Zhao, Y., Hennigan, C. J., May, A. A., Tkacik, D. S., de Gouw, J. A., Gilman, J. B., Kuster, W. C., Borbon, A., and Robinson, A. L.: Intermediate-volatility organic compounds: a large source of secondary organic aerosol, Environ. Sci. Technol., 48, 1374313750, 2014.

Zotter, P., El-Haddad, I., Zhang, Y. M., Hayes, P. L., Zhang, X., Lin, Y.-H., Wacker, L., Schnelle-Kreis, J., Abbaszade, G., Zimmermann, R., Surratt, J. D., Weber, R. J., Jimenez, J. L., Szidat, S., Baltensperger, U., and Prévôt, A. S. H.: Diurnal cycle of fossil and nonfossil carbon using radiocarbon analyses during CalNex, J. Geophys. Res.-Atmos., 119, 6818-6835, 2014. 